\title{
Summary of the Tandem Cylinder Solutions from the Benchmark problems for Airframe Noise Computations-I Workshop
}

\author{
David P. Lockard* \\ NASA Langley Research Center, Hampton, VA 23681
}

\begin{abstract}
Fifteen submissions in the tandem cylinders category of the First Workshop on Benchmark problems for Airframe Noise Computations are summarized. Although the geometry is relatively simple, the problem involves complex physics. Researchers employed various block-structured, overset, unstructured and embedded Cartesian grid techniques and considerable computational resources to simulate the flow. The solutions are compared against each other and experimental data from 2 facilities. Overall, the simulations captured the gross features of the flow, but resolving all the details which would be necessary to compute the noise remains challenging. In particular, how to best simulate the effects of the experimental transition strip, and the associated high Reynolds number effects, was unclear. Furthermore, capturing the spanwise variation proved difficult.
\end{abstract}

\section{Nomenclature}

$\begin{array}{ll}A & \text { cross-sectional area } \\ L_{z} & \text { span } \\ \mathrm{C} 1 & \text { upstream Cylinder } \\ \mathrm{C} 2 & \text { downstream Cylinder } \\ C_{D} & \text { drag coefficient } \\ C_{L} & \text { lift coefficient } \\ C_{p} & \text { pressure coefficient } \\ \mathrm{D} & \text { cylinder diameter } \\ \mathrm{L}_{\mathrm{z}} & \text { spanwise length } \\ \mathrm{LFOV} & \text { large field of view } \\ M & \text { Mach number } \\ p & \text { pressure } \\ R_{p p} & \text { spanwise correlation of pressure } \\ \text { TKE } & \text { turbulence kinetic energy }\end{array}$

$$
\begin{array}{ll}
u, v & \text { Cartesian fluid velocity components } \\
U, V & \text { time-averaged velocity components } \\
|\mathbf{V}| & \text { magnitude of the velocity vector } \\
x, y, z & \text { Cartesian coordinates }
\end{array}
$$

Greek:

$\rho \quad$ fluid density

$\theta \quad$ azimuthal angle

$\omega_{z} \quad$ spanwise vorticity

Superscript:

$$
\text { , perturbation quantity (e.g. } \rho^{\prime}=\rho-\rho_{o} \text { ) }
$$

Subscript:

o freestream quantity

\section{Introduction}

The First Workshop on Benchmark problems for Airframe Noise Computations (BANC-I) was held in Stockholm, Sweden, on June 10-11, 2010. The workshop was organized by the Discussion Group on Benchmark Experiments and Computations for Airframe Noise (BECAN), ${ }^{1}$ which is jointly sponsored by the Fluid Dynamics and Aeroacoustics Technical Committees of AIAA.

With continued progress in engine noise reduction, airframe noise has emerged as an important contributor to the overall acoustic signature of an aircraft. The geometric and physical complexity of airframe noise sources represents a significant obstacle to accurate and efficient high-fidelity aeroacoustic simulations, imposing particularly stringent requirements on the scope, accuracy and level of detail of the measurement database needed to validate these simulations in a systematic manner. The BECAN discussion group was established as a grass roots effort to identify a common set of airframe noise configurations for collective investigations, facilitate the joint acquisition of suitable benchmark datasets, and coordinate computational investigations.

The BANC-I workshop represents the first tangible milestone under this collective effort and was designed to accomplish the following objectives:

1. Provide a forum for a thorough assessment of simulation-based noise-prediction tools in the context of airframe configurations including both near-field unsteady flow and the acoustic radiation generated via the interaction of this flow

*Research Scientist, Computational AeroSciences Branch, Mail Stop 128, Senior Member, AIAA 
with solid surfaces.

2. Identify current gaps in physical understanding, experimental databases and prediction capability for the major sources of airframe noise, and to contribute advances to bridge those gaps.

3. Help determine best practices and most promising techniques for computational and experimental studies of airframe noise, and accelerate the development of benchmark quality datasets.

4. Promote future coordinated studies of common configurations for maximum impact on the current state of the art in the understanding and prediction of airframe noise.

The following four problem categories were selected for the first workshop:

1. Airfoil trailing edge noise,

2. Tandem cylinders,

3. Rudimentary landing gear and

4. Partially-dressed, cavity-closed nose landing gear.

The BANC-I workshop was attended by over eighty-five researchers from fourteen countries. Eight government organizations from Asia, Europe and the United States, five major industry organizations, five software vendors, and a number of academic institutions participated in the workshop. A broad set of computational techniques were applied to a common set of problems, spanning structured, unstructured, overset and Cartesian grid solvers, low- and high-order algorithms, Large Eddy Simulation (LES) and hybrid Reynolds Averaged Navier-Stokes (RANS)/LES methods. Most evident was the community spirit in coming together to support the BECAN goals and, in particular, the paradigm shift in benchmark activities for computational aeroacoustics, from closed form analytical solutions and single facility, single organization experiments, to collaboratively planned, multi-facility, multi-group experiments.

The purpose of this paper is to summarize the numerical solutions to the tandem cylinder problem. A summary of the rudimentary landing gear solutions is available in Ref. 2. Additional information about the individual workshop presentations and papers can be found at the BECAN website. ${ }^{1}$

\section{Tandem Cylinder Problem Definition}

The simulated tandem cylinder configuration is comprised of two cylinders of equal diameter (D) aligned along the streamwise direction. The diameter of the cylinders is 2.25 inches $(0.05715 \mathrm{~m})$. The geometry under consideration is shown in Fig. 1. The separation distance, L, between the cylinders is $3.7 \mathrm{D}$. The angle $\theta$ is measured from the upstream stagnation point and is positive in the clockwise direction.

Experiments by Jenkins et al, ${ }^{3,4}$ and Neuhart et al. have been performed in the Basic Aerodynamic Research Tunnel (BART) at NASA Langley Research Center, providing steady surface pressures, detailed off-surface measurements of the flow field using Particle Image Velocimetry (PIV), hot-wire measurements in the wake of the downstream cylinder and unsteady surface pressure data. The BART is a subsonic, atmospheric wind tunnel used to investigate the fundamental characteristics of complex flow fields (see Fig. 2(a)). The tunnel has a closed test section with a height of 28 inches $(0.711 \mathrm{~m})$, a width of 40 inches $(1.016 \mathrm{~m})$ and a length of 120 inches $(3.048 \mathrm{~m})$. The free stream velocity was set to $144 \mathrm{ft} / \mathrm{s}(44 \mathrm{~m} / \mathrm{s})$ to achieve a Reynolds number based on cylinder diameter of $1.66 \times 10^{5}$. At these conditions the free stream turbulence level was less than $0.10 \%$. The cylinders spanned the entire BART tunnel height, such that the aspect ratio during the experiment was $\mathrm{L}_{\mathrm{z}} / D=12.4$. To ensure a fully turbulent shedding process, the boundary layers on the upstream cylinder were tripped between azimuthal locations of 50 and 60 degrees from the leading stagnation point using a transition strip with features and dimensions shown in Fig. 3. Experimental results are available for cases with only the front cylinder tripped and with both cylinders tripped. The measured surface pressure distribution for an isolated cylinder was nearly identical to that measured by previous investigators for Reynolds numbers greater than eight million. ${ }^{6}$

The tandem cylinder arrangement tested in the BART was also investigated in NASA LaRC's anechoic wind tunnel, the Quiet Flow Facility (QFF). The QFF is an open jet facility specifically designed for anechoic testing and is equipped with a $2 \mathrm{ft}(0.61 \mathrm{~m}) \times 3 \mathrm{ft}(0.914 \mathrm{~m})$ rectangular open jet nozzle. The test models were supported above the nozzle by two vertical side plates that were mounted to the short sides of the nozzle (see Fig. 2(b)). The cylinders spanned the 3 $\mathrm{ft}(0.914 \mathrm{~m})$ section yielding an aspect ratio of $\mathrm{L}_{\mathrm{z}} / D=16$. To simulate the BART results as closely as possible, the trip arrangement on the front cylinder was duplicated, and the speed in the tunnel was adjusted until the shedding frequency was matched. The nominal Mach number for the test was $0.1274(43.4 \mathrm{~m} / \mathrm{s})$ with a dynamic pressure of $0.166 \mathrm{psi}(1145$ $\mathrm{Pa}$ ). Steady and unsteady surface pressure data from the QFF compared relatively well with the results from the BART. Additionally, acoustic data were collected in the QFF with three fixed microphones and a traversing microphone.

For the selected separation distance of $\mathrm{L}=3.7 \mathrm{D}$ between the cylinder axes, the flow around the upstream cylinder is 
relatively unaffected by the downstream cylinder and experiences regular vortex shedding. Nonetheless, this challenges computational codes to properly simulate the turbulent boundary layer development, flow separation, and shear layer roll-up. If the flow separates too early, the shear layers will spread too far apart and dramatically change the downstream wake.

Although the cylinder configuration is predominantly two-dimensional, three-dimensional effects are important throughout the domain and cannot be ignored. The correlation of the surface pressure between two points separated in the spanwise direction gradually approaches zero as the spacing between the points increases to 7 diameters. Ideally, calculations would employ a spanwise extent of similar order to the experiments. The span was $12.4 \mathrm{D}$ in the closedwind tunnel and $16 \mathrm{D}$ in the open-jet tunnel. However, the computational cost for using a large spanwise extent can be prohibitive. Previous computations ${ }^{7}$ have shown that some of the important flow features can be captured with a span of $3 \mathrm{D}$. Therefore, the standard span length for the workshop was specified as $\mathrm{L}_{\mathrm{z}}=3$ cylinder diameters with periodic boundary conditions, but researchers were strongly encouraged to use larger domains in addition to $L_{z}=3 \mathrm{D}$.

With the flow dynamics from the upstream cylinder properly captured, calculations must then propagate the wake to the downstream cylinder and properly simulate the interaction with the solid surface. Although this interaction dominates the flow around the downstream cylinder, viscous boundary layer development is still important. Because the upstream cylinder experiences fairly regular vortex shedding, the interaction of these shed vortices with the downstream cylinder is also fairly regular. Hence, the surface pressure spectra and radiated noise exhibit strong spectral peaks at the primary shedding frequency, which is on the order of $200 \mathrm{~Hz}$. There is a broadband component to the spectra, but it is at a much lower level. The acoustic directivity closely resembles the dipole shape observed for an isolated cylinder.

The detailed problem statement as well as the experimental data provided to the participants can be found at the AIAA BECAN web site. ${ }^{1}$

\section{Participants}

Fifteen groups submitted solutions in the tandem cylinder category. Contributors included software vendors (CD Adapco and EXA Corp.), government research organizations (ONERA, JAXA, NASA and DLR), universities (Universite catholique de Louvain (UCL), Florida State University (FSU), University of Southampton, Technical University of Berlin (TUB) and Stanford), as well as New Technologies and Services (NTS) of the St.-Petersburg State Polytechnic University. The contributors are listed in Table 1 and some details about the computations are listed in Tables 2, 3 and 4. Only the surname of the first submitter is listed although many of the submissions were prepared by multiple researchers. Additionally, some groups submitted multiple solutions, but only the best representative solutions identified by the submitters have been included in this summary. The information about the Stanford submission by Christopher C. Yu et al. is not included. They performed a high-order LES, but were unable to implement a satisfactory numerical tripping mechanism that would simulate the high Reynolds number aspects of the flow without adverse affects. A. Uzun of FSU, T. Imamura of JAXA and M. Terracol of ONERA had similar experiences with pure LES simulations. Only the ONERA LES solutions are included in this summary as the other groups resorted to hybrid RANS/LES methods. The groups intend to further investigate numerical trips, and their efforts are likely to be reported in future workshops and in other publications.

In Table 2, the columns labeled as "order" refer to the order of the truncation error of a Taylor series representation of the derivative operators used in the convective and viscous terms in the Navier-Stokes equations as well in turbulence model terms. Most of the codes used second-order operators, but reduced the order to unity for some of the terms in the turbulence model. The NTS code $(8 \mathrm{a}$ and $8 \mathrm{~b})$ used a hybrid combination of a 4th-order central difference and a 5th-order upwind operator for the convective terms in the Navier-Stokes equations. OVERLOW employed a 5th-order weighted essentially non-oscillatory (WEN05M) method for the convective terms in the flow equations. Blank entries were either not reported or not applicable for the given code. Most of the grids used in the studies were comprised of either block-structured or overset structured grids. Embedded Cartesian grids employed a factor of two refinement between levels of uniform, Cartesian grids that were immersed inside each other. The unstructured grids included both fully tetrahedral and mixed-element grids.

Table 3 gives additional details about the computations. The ID numbers and names of the codes will be used to identify the submissions in the remainder of the paper. For the unnamed in-house codes, the organization will be used. The 8-NTS code and 12-OpenFOAM were run in an incompressible mode. All of the other codes were run using a compressible formulation, although some used low Mach number approximations. All of the submissions employed some sort of Hybrid RANS/LES method except for the pure LES computations. Most of the submissions used some variant of the Detached-Eddy Simulation ${ }^{8}$ (DES) approach, with Delayed-DES ${ }^{9}$ (DDES) being the most popular. The Improved-DDES ${ }^{10}$ and Modified-DDES ${ }^{11}$ (MDDES) were also represented. Two submissions used a zonal or quasi- 
laminar ${ }^{12}$ approach where the turbulence model production term is set to zero outside of boundary layers. The flowsimulation methodology ${ }^{13}$ (FSM) and HRLES ${ }^{14}$ hybrid methods were also represented. Although the majority of the researchers employed the Spalart-Allmaras ${ }^{15}$ (S-A) turbulence model, submissions also used Menter's ${ }^{16}$ two-equation Shear Stress Transport (SST) model and a $k-\epsilon$ model coupled with a Lattice-Boltzmann method. ${ }^{17}$

Several time-stepping methods were employed. Dual-time algorithms use Newton iterations to converge a pseudotime variable using steady-state acceleration techniques. Beam and Warming (B-W) and Gear variants were also employed instead of Newton iterations. A second-order, implicit Runge-Kutta (RKI2) method was also used along with the pisoFOAM method of OpenFOAM and the Matrix-Free Gauss-Seidel (MFGS) scheme.

Most of the computations were performed in a free-field more similar to the QFF configuration, but the grids used by the NTS, TUB and DLR groups included the tunnel walls from the BART configuration. However, they still employed periodicity in the spanwise direction. The minimum allowable span length for the computations was $3 \mathrm{D}$, but several of the simulations used much longer spans as indicated in Table 3. The associated number of grid points is reported in millions. Interestingly, because the simplicity of the geometry allowed for relatively easy grid generation, some of the grids employed for the tandem cylinder problem were much larger than those used for the more complicated geometries represented at the workshop. For example, the largest grid used for the nose landing gear had 70 million grid points, but 133 million were used in the tandem cylinder problem. Table 3 also reports the number of time steps required to simulate 1 second of flow along with the number of subiterations for each time step. Although the tandem cylinder geometry is relatively simple, the grid sizes and time steps give an indication of the true complexity of the problem. Furthermore, the wall clock time needed to generate 1 second of simulation data reported in Table 4 indicates the tremendous resources that have been expended. The codes were run on different hardware with vastly different domain and grid sizes, so the table is not meant to give an indication of relative efficiency.

\section{Results}

\section{IV.A. Density and Vorticity Contours}

Although not part of the requested data for the workshop, some of the participants provided contour plots of their flow. The images indicate some of the physics in the problem and provide a qualitative comparison of what the different methods are resolving. The density in an $x-y$ plane is shown in Fig. 4. The four results shown all indicate the large-scale roll-up of the shear layers coming off the upstream cylinder, but the small-scale features indicative of Kelvin-Helmholtz instabilities are much more pronounced in the 2-PowerFLOW and 6-OVERFLOW simulations. Grid resolution, the order of accuracy of the numerical scheme and the turbulence model all contribute to the ability of the method to resolve the small-scale features.

Density contours in an $x-z$ plane are presented in Fig. 5. Results from three calculations with the longest span lengths are represented. The 2-PowerFLOW result is at $y / D=0$, whereas the other results are at $y / D=0.35355$, intersecting the cylinders at $\theta=45^{\circ}$ and $135^{\circ}$. Considerable spanwise variation is evident within the periodic domains. Many of the features are relatively small, so capturing the spanwise variation is one of the more difficult aspects of the problem.

Images of the instantaneous spanwise vorticity, $\omega_{z} D / U_{o}$, are shown in Fig. 6. The PIV result from the BART shown in Fig. 6(a) exhibits both large- and small-scale features. Some of the simulation results display very similar distributions, while others have not resolved the small-scale features. The shear layer emanating from the upstream cylinder is relatively thin, and having enough points across the shear layer to capture the instability growth and breakup of the shear layer is challenging. Furthermore, the shear layers migrate up and down, increasing the difficulty. How well a simulation resolves the shear layer dynamics will have an important influence on the overall results.

\section{IV.B. Time-Averaged Surface Pressure}

In the subsequent comparisons, the submissions will be grouped based on the turbulence model. All of the computations that performed an S-A based DDES simulation will be compared together, and those with a different model will be presented together. The time-average of the coefficient of pressure, $C p$, for the S-A DDES computations is shown in Fig. 7. The results on the upstream cylinder are shown in Fig. 7(a), and the downstream cylinder in Fig. 7(b). On the upstream cylinder, other than the 7-ARGO result, the distributions are in remarkable agreement with each other and the experimental data. The base pressure agrees much better with the QFF experiment. There is slightly more scatter in the results on the downstream cylinder, and in this case the base pressure is more similar to the BART result. The 7-ARGO result again differs the most from the other results, and the reasons for the discrepancies are not known.

There are two experimental results for each tunnel included in Fig. 7(b) based on whether or not the downstream 
cylinder was tripped. Despite the significant unsteady wake impingement on the downstream cylinder, tripping still has a noticeable effect on the pressure distribution. The results with the trip (denoted as C2 Trip, open symbols) have less negative $C p$ values at the suction peaks in better agreement with the computational results. It should be noted that the participants were not provided with the data for the downstream cylinder tripped until after the workshop, although the BART data ${ }^{5}$ was available in the literature.

The $C p$ comparison for the simulations that did not employ the S-A DDES model are shown in Fig. 8. Although there is more scatter among these results, they still generally follow the experimental trends. The $C p$ distribution on the upstream cylinder is primarily a function of where the flow separates. The five submissions that employed an SST based turbulence model $(1,3,5 \mathrm{~b}, 11,12)$ all have suction peaks that are less negative than the experimental values, indicative of an early separation. The 2-PowerFLOW result is also slightly less negative than the experimental data at the suction peak, but they employed a roughness wall boundary condition on the upstream cylinder to promote the transition to turbulence. The particular set of parameters they chose to define the roughness is likely to be the controlling factor in their case. The pressure distribution on the downstream cylinder is strongly influenced by the wake from the upstream cylinder as well as the shedding on the downstream cylinder. Errors in the propagation of the wake from the upstream to downstream cylinder will contribute to differences in the simulations. The variations in the solutions on the downstream cylinder are likely to be caused by a combination of the turbulence model and resolution.

\section{IV.C. Surface Pressure Fluctuations}

The root-mean-square (rms) of the perturbations in $C p^{\prime}$ on the cylinder surfaces are presented in Fig. 9 for the S-A DDES simulations and in Fig. 10 for the other calculations. On the upstream cylinder, the peaks are associated with flow separation off the cylinder. On the downstream cylinder, the peaks around $\pm 45^{\circ}$ are associated with wake impingement, and the peaks around $\pm 110^{\circ}$ occur where the flow separates. Note that different vertical scales have been used for the upstream and downstream cylinders. Again, the S-A DDES results are in quite good agreement agreement with each other and the experimental data. Some of the high values in Fig. 10(a) are caused by the use of computational mechanisms (such as surface suction/blowing) to trip the flow. As indicated by Fig. 9(b) the S-A DDES simulations are in much better agreement with the experimental data with the downstream cylinder tripped. Without the trip, the secondary peak is slightly delayed and the rms levels are much higher. In Fig. 10(b), the LES result of 9-FUNk shows higher secondary peaks as did several other LES-type approaches that are not shown. The 2-PowerFLOW result also shows a significant secondary peak, but on the downstream cylinder they did not employ the rough-wall model in their wall-function implementation as they did for the upstream cylinder.

\section{IV.D. Surface Pressure Spectra}

The power spectral density ${ }^{18}$ (PSD) of the pressure on the upstream cylinder at $\theta=135^{\circ}$ is shown for the S-A DDES solutions in Fig. 11(a) and in 12(a) for the others. Not all of the submissions included the PSD, and some were not plotted because they were too oscillatory to include with the other results. The experimentalists speculate that the hump in the experimental levels between 400 and $2000 \mathrm{~Hz}$ is a result of the trip because it was not observed in untripped configurations. Other than that feature, the computational results are in general agreement with the experiments. However, the predicted primary shedding frequency and first harmonic are slightly different for some of the computations. The location of separation controls the shedding frequency, with later separation leading to more rapid shedding and higher frequencies. The peaks are not as distinct in the computational results because of the limited time records available from the simulations.

Compared with the upstream cylinder, the PSD's on the downstream cylinder from the S-A DDES computations are in better agreement with each other and the data as shown in Fig. 11(b). Note that $\theta=45^{\circ}$ is near where the wake from the upstream cylinder most strongly interacts with the downstream cylinder. The effect of a trip on the downstream cylinder did not affect the spectra at this location. The spectra in Fig. 12(b) from the codes using other turbulence models also show better agreement on the downstream cylinder than on the upstream one. The frequency of the tone is set by the shedding on the upstream cylinder, but other features of the spectra on the upstream cylinder do not seem to directly dictate the shape of the downstream spectra.

\section{IV.E. Spanwise Correlation of Surface Pressure}

A few of the participants submitted data on the spanwise correlation of the pressure at $\theta=135^{\circ}$ on both cylinders. The results in Fig. 13 include three of the simulations with spanwise extents of $16 \mathrm{D}$ or greater (4-UPACS-LES, 5b-CFL3D and 8b-NTS). However, because all of the simulations employed periodic boundary conditions in the spanwise direction, 
$R_{p p}$ can only be calculated up to half the span length. On both the upstream and downstream cylinders, the simulations with spans of $3 \mathrm{D}$ remain fairly well correlated across the entire domain. Clearly, the calculations with a span of 3 $\mathrm{D}$ cannot fully resolve all of the spanwise effects. The longer span simulations do show considerably more spanwise decorrelation, but only the 5b CFL3D result produces levels approaching zero. However, some of the other contributors have reported that running their simulations for more time steps resulted in lower correlation levels. The randomness in the simulations may be slowly increasing which requires even longer run times. The 5b-CFL3D simulation was initiated with random suction and blowing on the cylinder surfaces to promote a rapid transition to irregular shedding. The random forcing was only applied over a short time duration and before the code was run for a significantly long time period to wash out transients. Nonetheless, this procedure may have contributed to the lower correlation values observed in this calculation.

\section{IV.F. Streamwise Velocity}

Even amongst the S-A DDES results, the streamwise velocity distributions along the centerline, $y=0$, between the cylinders shown in Fig. 14(a) show considerable variation. In most of the results, the recirculation zone behind the upstream cylinder is larger than that observed in the BART Particle Image Velocimetry (PIV) measurement with a Large Field of View (LFOV). In the gap region, two LFOV regions were spliced together around $x=2$. An earlier experiment ${ }^{4}$ with a smaller cylinder diameter but a Mach number of 0.166 to maintain a Reynolds number of 166,000 showed differences of around $10 \%$ in the peak velocities in the gap. Behind the downstream cylinder (C2), data was obtained with both the LFOV and a smaller field of view with better resolution. Only the smaller field of view was used when the downstream cylinder was tripped. The velocity distributions shown in Fig. 14(b) are in very good agreement with the small field of view experimental result when the downstream cylinder was tripped. Considerable variation is observed around both cylinders in Fig. 15 for the codes using other turbulence models. Several of the simulation results downstream of $\mathrm{C} 2$ were in better agreement with the untripped $\mathrm{C} 2$ data. These cases also matched better with the untripped $\mathrm{C} 2 C p_{r m s}^{\prime}$ distributions in Fig. 10. The state on the downstream cylinder appears to be dependent on the turbulence model and boundary conditions on the cylinder.

\section{IV.G. 2D Turbulence Kinetic Energy}

A comparison of the 2D turbulence kinetic energy normalized by the free-stream velocity,

$$
2 \mathrm{D} \text { TKE }=\frac{1}{2}\left(<u^{\prime} u^{\prime}>+<v^{\prime} v^{\prime}>\right) /\left|\mathbf{V}_{\mathbf{o}}\right|^{2}
$$

is presented in Fig. 16. Only two component PIV data was collected in the BART experiments, so the equivalent information was calculated from the simulations. Although most of the codes employ some sort of subgrid scale model, the regions where the PIV data were collected are primarily LES regions dominated by the large-scale structures. Therefore, the TKE was calculated using the resolved portion of the fluctuations and neglecting the modeled portion.

In the gap region along $y=0$, most of the simulations predict peak levels with locations that are similar to what was observed in the experiment. Given the large variation in the streamwise velocity and the corresponding size of the recirculation zone behind the upstream cylinder as observed in Figs. 14(a) and 15(a), the agreement is better than expected. Downstream of C2, Fig. 16(b) reveals more variation between the simulation results. Furthermore, the peak levels indicated by the BART PIV with the smaller field of view are considerably higher than those of the LFOV result, and also what most of the simulations predict. Only the 2 PowerFLOW result displays fluctuation levels as high as those observed in the experiments with the smaller field of view. However, the predicted location of the peak from the other codes appears to be in better agreement with the higher resolution PIV data.

\section{IV.H. Acoustic Spectra}

Acoustic measurements from the QFF experiment were obtained at three microphone locations. To predict the noise, the simulations used their near-field data in some sort of acoustic analogy such as the Ffowcs Williams-Hawkings equation. ${ }^{19}$ As most of the simulations were performed with relatively short spans that did not capture the spanwise decorrelation, approximate methods ${ }^{20}$ that correct for the span length were employed. Only a few of the submissions included acoustic results, but Fig. 17 shows the level of agreement that can be achieved. The microphone position is (9.11D, 32.49D) from the centroid of the upstream cylinder. The agreement at the other microphone positions is similar. The periodic boundary conditions, span length, and short time records in the simulations limit how closely the simulations can be expected to agree with the experiment. Furthermore, the peak level in the experiment varied by $\pm 1 \mathrm{~dB}$ from run to run because of 
the intermittency in the signal. Nonetheless, the acoustic comparisons do give additional guidance on the quality of the simulations.

\section{Simulation Challenges}

The comparisons that have been shown do not give an indication of the effort that the participants expended, nor the difficulties that were encountered. Many submissions included grid and time step refinements, studies with different turbulence models, and calculations with different span lengths. As an example of an interesting difficulty that was encountered, Fig. 18 shows the streamlines and time-averaged velocity magnitude contours for two different states observed in 5a-CFL3D simulations. Several contributors reported observing similar states. State 1 is the one observed in the experiment where the wake from the upstream cylinder closes in the gap region, and the cylinders shed independently. In State 2, the wake of the upstream cylinder attaches to the downstream cylinder, and they act as a single body to the flow. State 2 was observed in the BART experiments, but only for much shorter cylinder separation distances. The $\mathrm{L}=$ 3.7 D case was chosen because State 1 was robust, without any indication of alternating between states. However, some other experiments at different Reynolds numbers and span lengths have observed State 2 with $\mathrm{L}=3.7 \mathrm{D}$. Some of the simulations transitioned between the States, and others preferred State 2. One contributor reported that he could only obtain State 1 on a certain grid, and State 2 on another grid. The grid, turbulence model and numerics are all playing a role in determining what state a simulation develops.

\section{Summary of Results}

The lift and drag from the simulations are compared in a more quantitative manner in Table 5 for the upstream cylinder and Table 6 for the downstream cylinder. The force coefficients are defined by

$$
C_{L}=\frac{\text { Lift }}{1 / 2 \rho\left|\mathbf{V}_{o}\right|^{2} A} \text { and } C_{D}=\frac{\text { Drag }}{1 / 2 \rho|\mathbf{V}|_{o}^{2} A}
$$

where $A$ is the cross-sectional area of the cylinder and $\mathbf{V}_{o}$ is the magnitude of the freestream velocity vector. The table lists the maximum, minimum, median, mean and standard deviation of the computational results. The standard deviation is also represented as a percentage of the mean value, and the mean and median are expressed as percentages of the experimental value when available. Unfortunately, no force data is available from the experiments. The shedding frequency measured in the experiments was $178 \mathrm{~Hz}$ which compares very well with both the mean and median values from the simulations listed in Table 5. The $C_{D}$ values for both cylinders are well below unity as would be expected for a high Reynolds number flow. The rms of the fluctuating lift and drag as well as the rms of the time derivative of the lift and drag are also presented in the tables. The amplitude of the oscillations and their time rate of change should influence the radiated noise. Different spanwise correlations will influence the derivative quantities, so the different span lengths in the simulations is a likely contributor to the variations observed in those quantities. The derivative quantities should have been evaluated at a single spanwise station, but the information was requested after the workshop. Only the data averaged over the full span of the simulations were available. Nonetheless, the difference between the two NTS simulations ( $8 \mathrm{a}$ and $8 \mathrm{~b}$ ) with spans of $3 \mathrm{D}$ and $16 \mathrm{D}$ are not nearly as great the differences between other simulations. For most of the quantities, the standard deviation normalized by the mean appears much higher for the upstream cylinder, but that is because the mean value is much lower. Small mean values can overemphasize the differences, so the magnitude of the standard deviation should also be considered.

Table 7 summarizes the results presented graphically earlier for the mean and rms surface pressure coefficient and streamwise velocity. For each variable, when meaningful, maximum and minimum values from each of the simulations and experiments are listed. Only the BART tests form a complete set, and the measurements with the downstream cylinder tripped match best with the majority of the simulations. Therefore, the BART data with C2 tripped are taken as the baseline. The median, which is less sensitive to outliers, is within $10 \%$ of the experiment for all quantities except the maximum $C p$ on the downstream cylinder. The experimental $C p$ is only 0.14 which exaggerates the standard deviation/mean. The standard deviation is actually relatively small compared with those for the other $C p$ values.

Although the collective median is in relatively good agreement with the experiments, no individual code's results compare as favorably with all aspects of the experiments. Additionally, there is considerably variation in the simulation results, and without such a large sample of solutions, one would have difficulty assessing which is better. On the other hand, all of the simulations captured the gross features observed in the experiments and would yield valuable information about the flow, although perhaps only qualitatively. 


\section{Conclusions}

The apparent simplicity of the problem is deceptive as all of the participants quickly learned and confirmed at the workshop. Most of the researchers tried different techniques to simulate the effects of the transition strip used in the experiments to produce a flow similar to that observed at Reynolds numbers above 8 million. No group attempted to run their calculations at very high Reynolds number because of the small grid spacing that would be required near the walls. Most resorted to using hybrid RANS/LES methods without a transition model. The S-A DDES method proved to be relatively successful at predicting the correct separation points and $C p$ distributions on the cylinders, and the S-A DDES results across different code and grid types were in good agreement. The pure LES computations had the most difficulty simulating the high Reynolds aspects of the flow. Several techniques were tried in the LES computations to rapidly induce the transition to turbulence, but they often produced undesirable side-effects. Different methods are being investigated and will likely be reported in future papers. The extensive use of hybrid RANS/LES methods indicates the importance and difficulty of properly modeling boundary layer effects and the associated pressure distributions at high Reynolds numbers.

Several features of the tandem cylinder problem present resolution challenges. Small-scale, Kelvin-Helmholtz instabilities grow in the shear layers that separate off the cylinders, and the wake must be propagated to the downstream cylinder without excessive diffusion. Furthermore, important spanwise variation occurs over many cylinder diameters. The number of grid points needed to resolve all of the small features can easily be in the hundreds of millions. Furthermore, the problem is unsteady requiring many time steps to acquire a sufficiently long sample to compute the statistics. Also, the periodic boundary conditions employed in nearly all the simulations undoubtedly have some nonphysical effect on the flow. Several of the groups are attempting to run simulations with either inviscid or viscous side walls and the full span from the experiments. Initial results seem to indicate that the end treatment does affect the spanwise correlation.

Even though not all of the available experimental data were used in this report, the breadth of the comparisons indicate the advantages of being able to examine multiple quantities. Although the $C p$ distributions from the S-A DDES simulations were in good agreement with each other and the data, considerable variation was observed in the streamwise velocity between the cylinders. The relatively comprehensive database allows simulations to be scrutinized more thoroughly and helps to identify deficiencies that might otherwise go unnoticed.

Nonetheless, many of the researchers requested additional experimental data. The data with a transition strip on the downstream cylinder was not initially distributed, but the available data were collected and included in this report, including the smaller field of view PIV data. The large and smaller field of view PIV data exhibit some substantial differences in both the streamwise velocity and 2D TKE. Hopefully, future measurements will reduce the uncertainties in these measurements so that comparisons with computations can be more quantitative. Skin friction, force measurements, and hot-wire spectra at specific locations are desired, but new experiments would be needed to obtain this information. The hope is that the tandem cylinders will be tested in additional facilities and with alternate techniques that will further enhance the already substantial experimental database that is currently available.

The general consensus is that the tandem cylinder configuration is a difficult test case that requires considerable effort to simulate, both in terms of pre-testing to guide the approach and in computational resources. Nonetheless, the problem is within reach of many groups as the number of submissions indicates. Furthermore, the purpose of the BANC workshops is to move beyond simple flows of little practical interest, and the tandem cylinders includes many realistic flow features while still remaining tractable. Overall, the workshop provided an excellent forum for the aeroacoustics community to come together and collectively learn from each others' experiences.

\section{Acknowledgments}

The author would like to thank all the participants for their efforts in simulating the tandem cylinder configuration and their useful comments and recommendations. The preparation of this paper was supported by the NASA Fundamental Aeronautics Program's Subsonic Fixed-Wing Project.

\section{References}

\footnotetext{
1"Discussion Group on Benchmark Experiments and Computations for Airframe Noise," URL: https://info.aiaa.org/tac/ASG/FDTC/DG/BECAN.aspx [cited December 2010].

${ }^{2}$ Spalart, P. R., Strelets, M., and Shur, M. L., "Analysis of Experimental and Numerical Studies of the Rudimentary Landing Gear to Validate Noise Predictions," 49th AIAA Aerospace Sciences Meeting, American Institute of Aeronautics and Astronautics, Reston, VA (submitted for publication), 2011.

${ }^{3}$ Jenkins, L. N., Khorrami, M. R., Choudhari, M. M., and McGinley, C. B., "Characterization of Unsteady Flow Structures Around Tandem
} 
Cylinders for Component Interaction Studies in Airframe Noise," AIAA Paper 2005-2812, 2005.

${ }^{4}$ Jenkins, L. N., Neuhart, D. H., McGinley, C. B., Choudhari, M. M., and Khorrami, M. R., "Measurements of Unsteady Wake Interference Between Tandem Cylinders," AIAA Paper 2006-3202, 2006.

${ }^{5}$ Neuhart, D., Jenkins, L., Choudhari, M., and Khorrami, M., "Measurements of the Flowfield Interaction Between Tandem Cylinders," AIAA Paper 2009-3275, 2009.

${ }^{6}$ Roshko, A., "Experiments On The Flow Past A Circular Cylinder At Very High Reynolds Number," Journal of Fluid Mechanics, Vol. 10, 1961, pp. 345-356.

${ }^{7}$ Lockard, D. P., Khorrami, M. R., Choudhari, M. M., Hutcheson, F. V., Brooks, T. F., and Stead, D. J., "Tandem Cylinder Noise Predictions," AIAA Paper 2007-3450, 2007.

${ }^{8}$ Spalart, P. R., Jou, W.-H., Strelets, M., and Allmaras, S. R., "Comments on the Feasibility of LES for Wings, and on a Hybrid RANS/LES Approach," Advances in DNS/LES, Aeroacoustics and Aeroelasticity of Turbomachines, edited by C. Liu, Z. Liu, and L. Sakell, Gryden Press, 1997, pp. 137-147, First AFSOR Conference on DNS/LES, Reston, LA, USA, Aug 4-8.

${ }^{9}$ Spalart, P. R., Deck, S., Shur, M. L., Squires, K. D., Strelets, M., and Travin, A. K., "A New Version of Detached-eddy Simulation, Resistant to Ambiguous Grid Densities," Theoretical Computional Fluid Dynamics, Vol. 20, 2006, pp. 181-195.

${ }^{10}$ Shur, M. L., Spalart, P. R., Strelets, M., and Travin, A. K., "A Hybrid RANS-LES Approach with Delayed-DES and Wall-Modelled LES Capabilities," International Journal of Heat and Fluid Flow, Vol. 29, 2008, pp. 1638-1649.

${ }^{11}$ Vatsa, V. N. and Lockard, D. P., "Assessment of Hybrid RANS/LES Turbulence Models for Aeroacoustics Applications," AIAA Paper 20104001, 2010

${ }^{12}$ Khorrami, M. R., Lockard, D. P., Choudhari, M. M., Jenkins, L. N., Neuhart, D. H., and McGinley, C. B., "Simulations Of Bluff Body Flow Interaction For Noise Source Modeling," AIAA Paper 2006-3203, 2006.

${ }^{13}$ Weinmann, M., Sandberg, R. D., and Doolan, C., "Flow and Noise Prediction for a Tandem Cylinder Configuration Using Novel Hybrid RANS/LES Approaches," AIAA Paper 2010-3787, 2010.

${ }^{14}$ Lynch, C. R. and Smith, M. J., "Hybrid RANS-LES Turbulence Models on Unstructured Grids," AIAA Paper 2008-3854, 2008.

${ }^{15}$ Spalart, P. R. and Allmaras, S., "A One-Equation Turbulence Model for Aerodynamic Flows," Recherche Aerospatiale, Vol. 1, No. 1, 1994, pp. $5-21$.

${ }^{16}$ Menter, F. R., "Two-Equation Eddy-Viscosity Turbulence Models for Engineering Applications," AIAA Journal, Vol. 32, No. 8, 1994, pp. 15981605.

${ }^{17}$ Bres, G. A., Wessels, M., and Noelting, S., "Predictions Using Lattice Boltzmann and Ffowcs Williams-Hawkings Methods," AIAA Paper 2010-3791, 2010

${ }^{18}$ Bendat, J. S. and Piersol, A. G., Engineering Applications of Correlation and Spectral Analysis, chap. 3, John Wiley \& Sons, 2nd ed., 1993, pp. 43-77.

${ }^{19}$ Ffowcs Williams, J. E. and Hawkings, D. L., "Sound Generation by Turbulence and Surfaces in Arbitrary Motion," Philosophical Transactions of the Royal Society, Vol. A264, No. 1151, 1969, pp. 321-342.

${ }^{20}$ Seo, J. H., Chang, K. W., and Moon, Y. J., “Aerodynamic Noise Prediction for Long-Span Bodies,” AIAA Paper 2005-2573, 2006. 

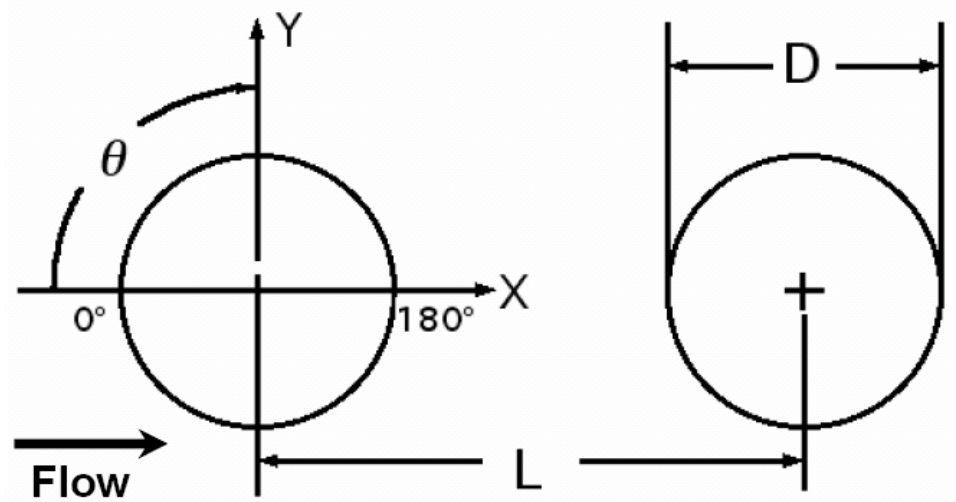

Figure 1. Schematic of tandem cylinder configuration.

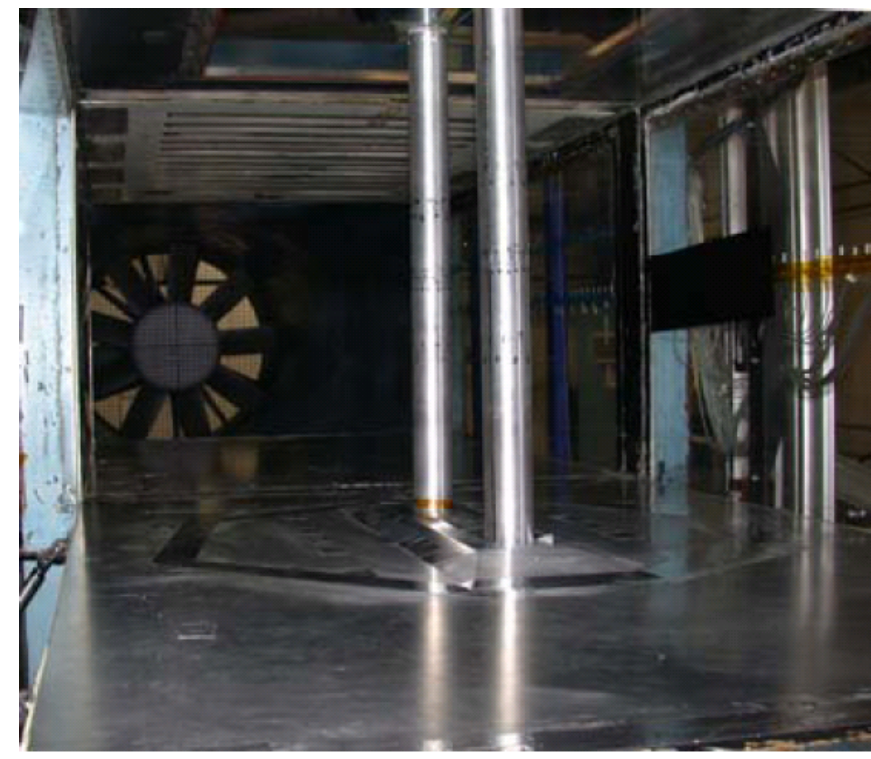

(a) BART

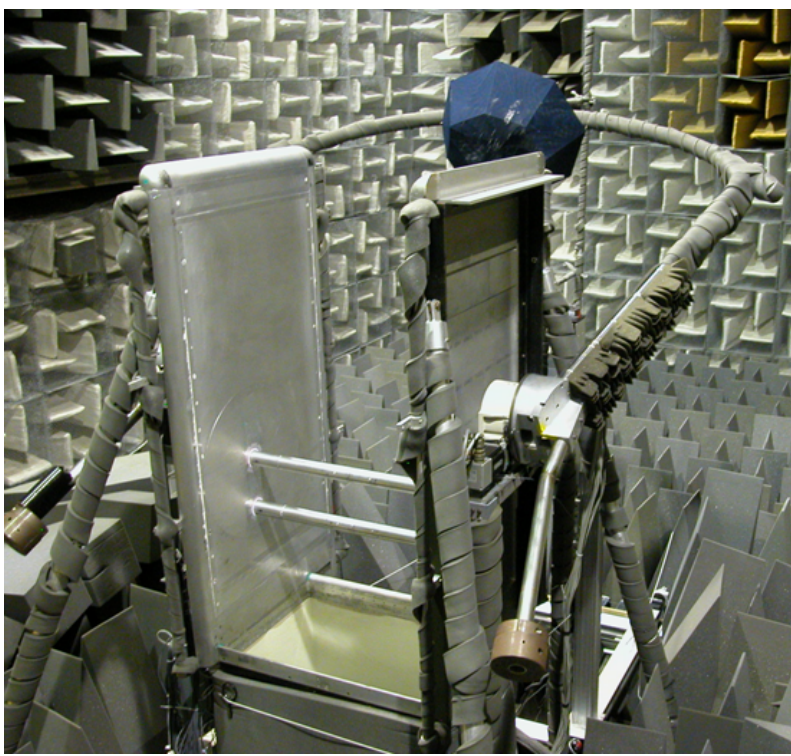

(b) QFF

Figure 2. Tandem cylinder arrangement in the Basic Aerodynamic Research Tunnel and Quiet Flow Facility.

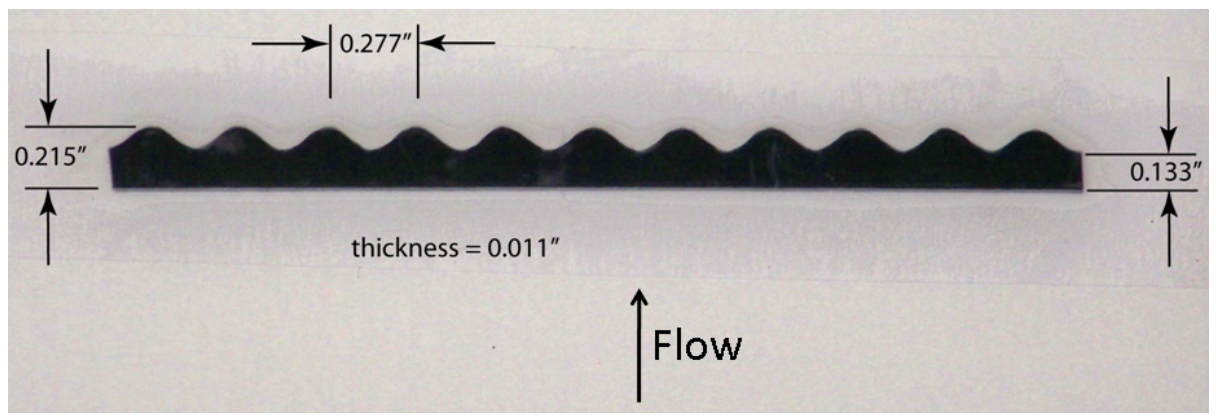

Figure 3. Details of the transition strip. 


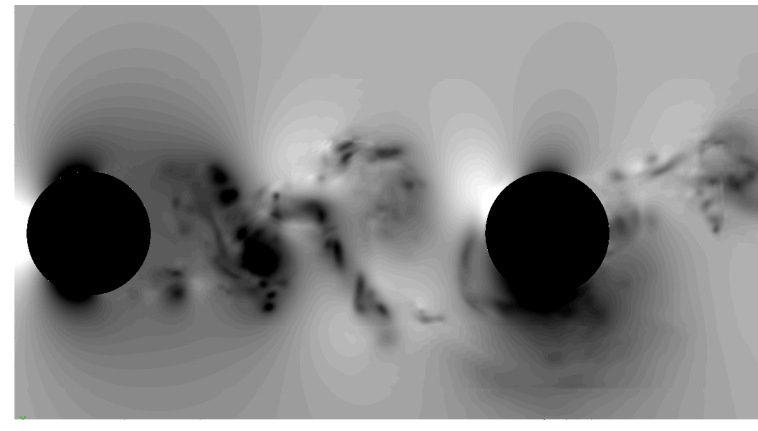

(a) 2-PowerFLOW

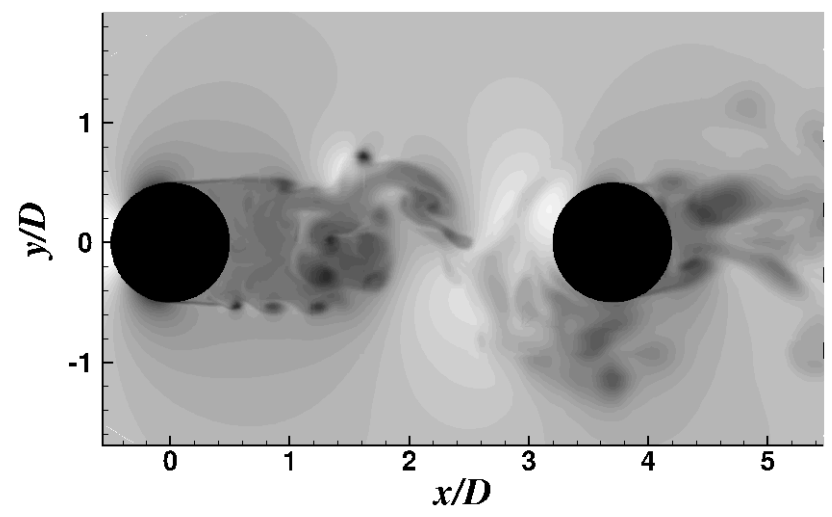

(c) $5 \mathrm{~b}-\mathrm{CFL} 3 \mathrm{D}$

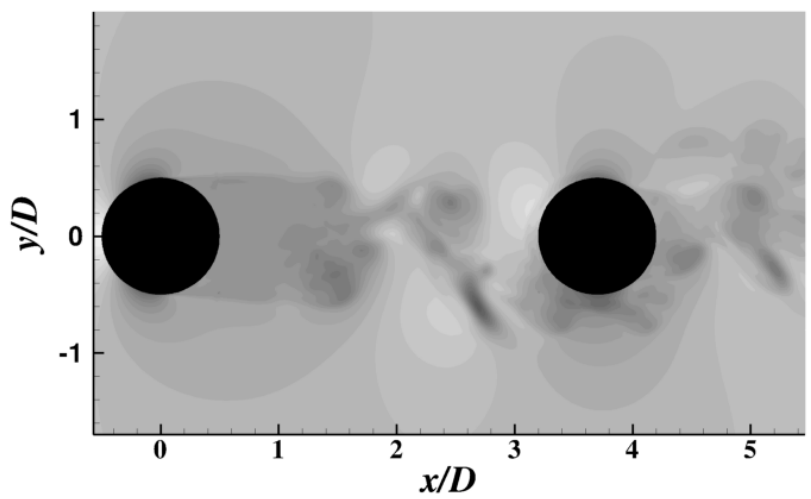

(b) 4-UPACS-LES

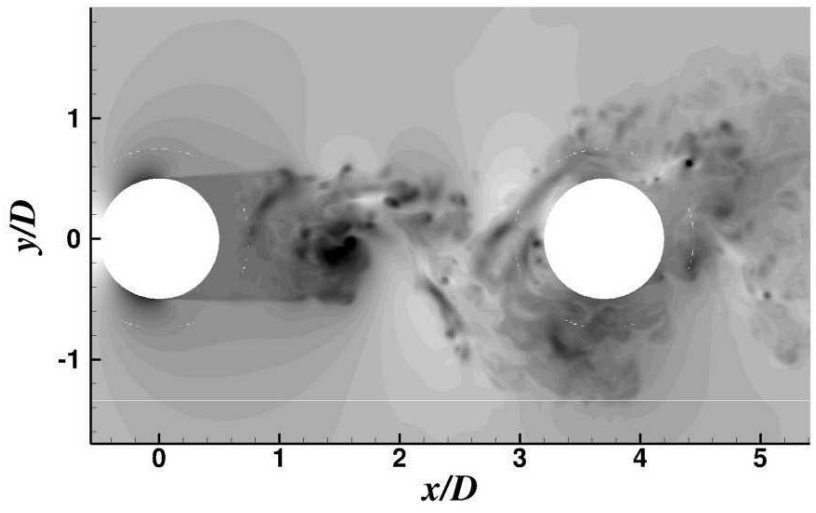

(d) 6-OVERFLOW

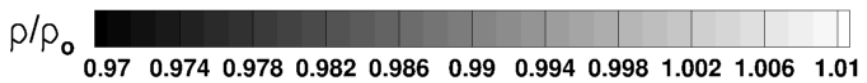

Figure 4. Instantaneous density contours in the $x-y$ plane.

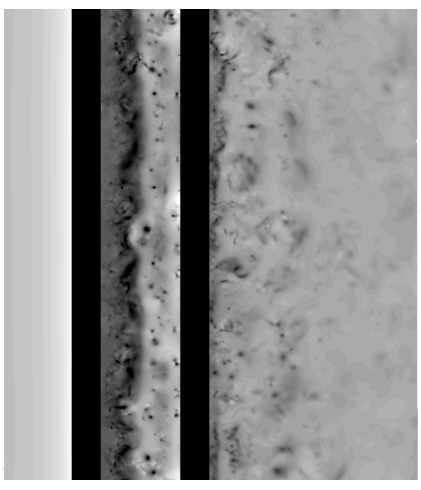

(a) 2-PowerFLOW, $y / D=0$

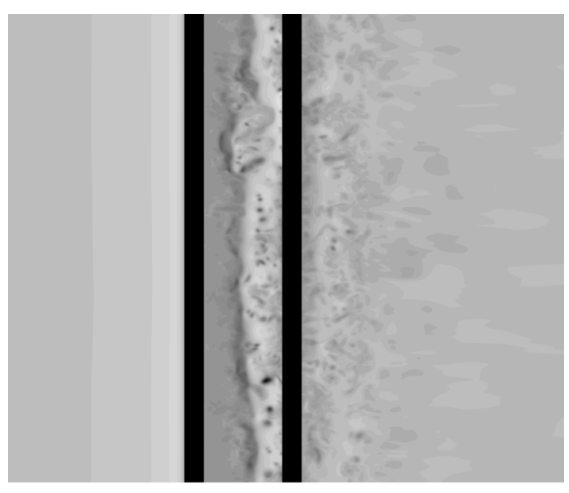

(b) 4-UPACS-LES, $y / D=0.35355$

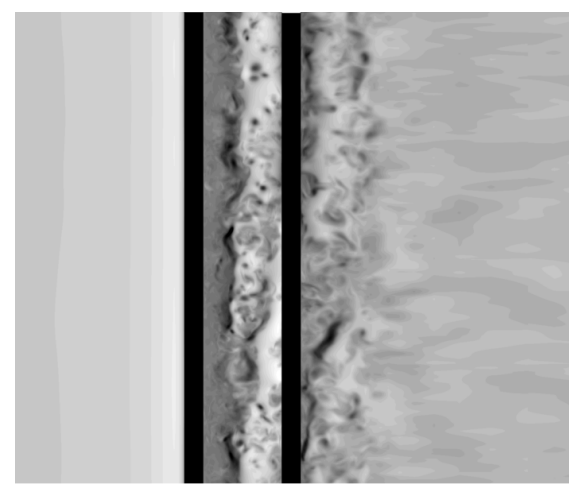

(c) 5b-CFL3D, $y / D=0.35355$

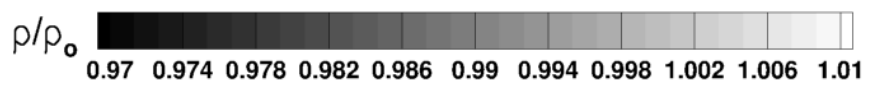

Figure 5. Instantaneous density contours in the $x-z$ plane 


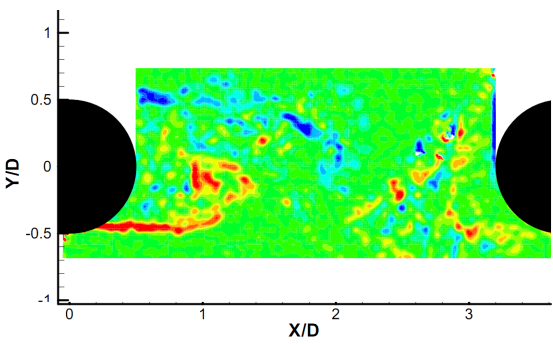

(a) BART PIV

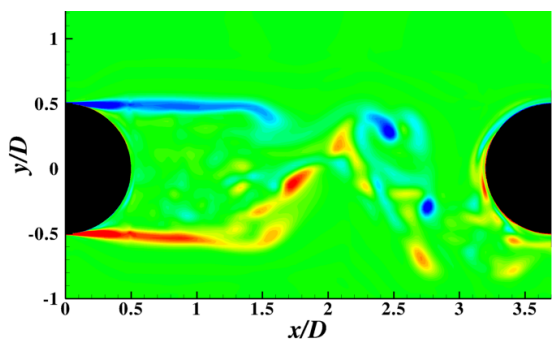

(d) 4-UPACS-LES

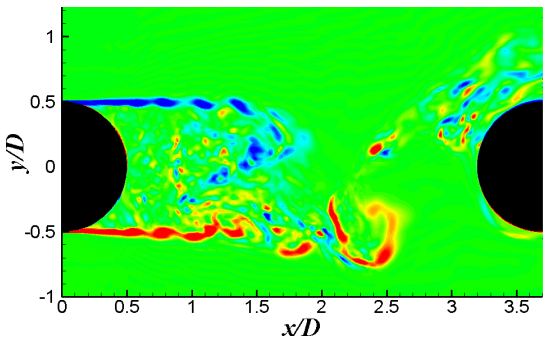

(g) $8 \mathrm{a}-\mathrm{NTS}$

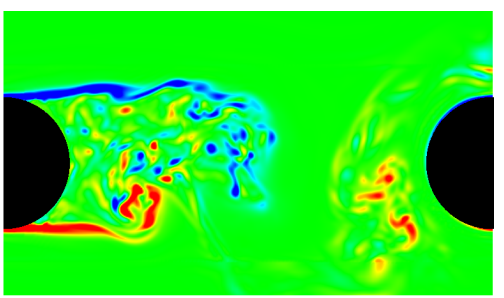

(b) 2-PowerFLOW

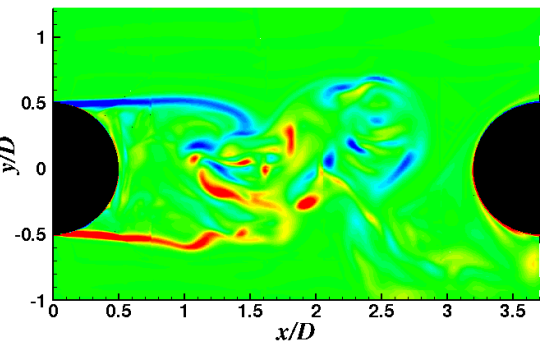

(e) $5 \mathrm{~b}-\mathrm{CFL} 3 \mathrm{D}$

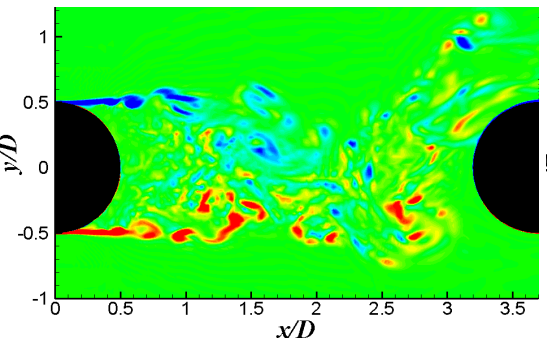

(h) $8 \mathrm{~b}-\mathrm{NTS}$

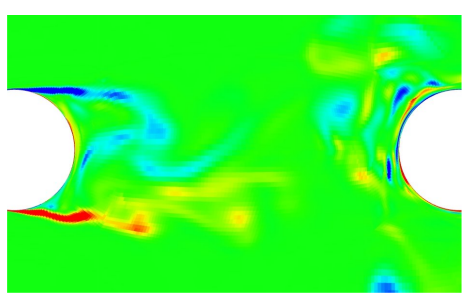

(c) 3-CEDRE

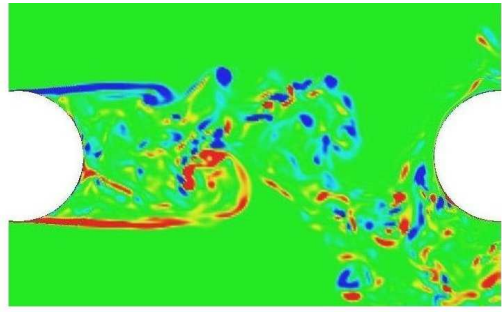

(f) 6-OVERFLOW

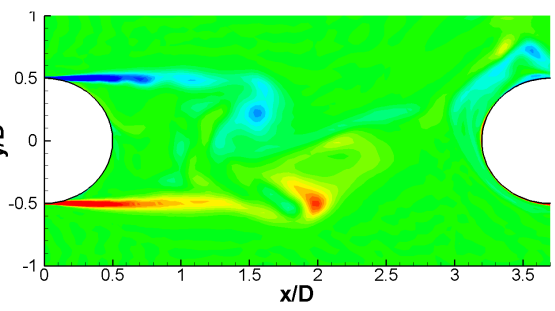

(i) 12-OpenFOAM

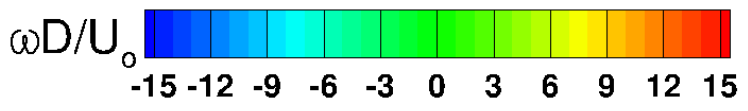

Figure 6. Instantaneous z-vorticity contours in the $x-y$ plane.

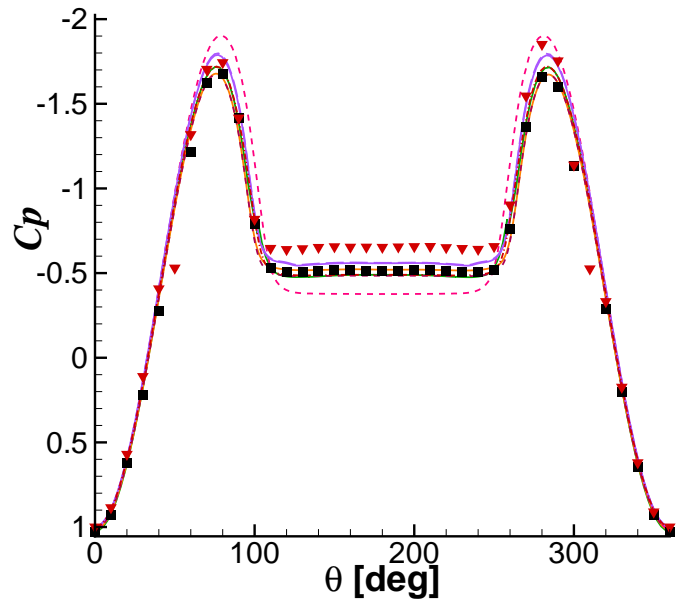

(a) Upstream Cylinder

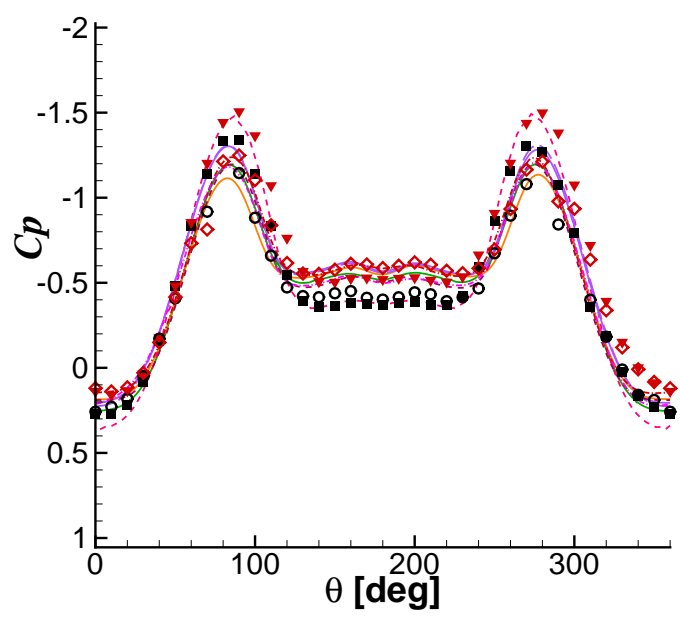

(b) Downstream Cylinder

Figure 7. Time-averaged coefficient of pressure on both cylinders from codes using S-A DDES. 


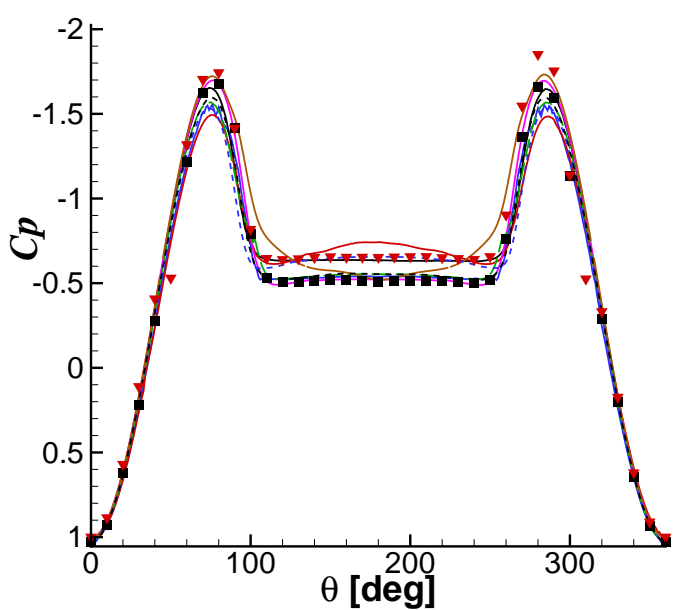

(a) Upstream Cylinder

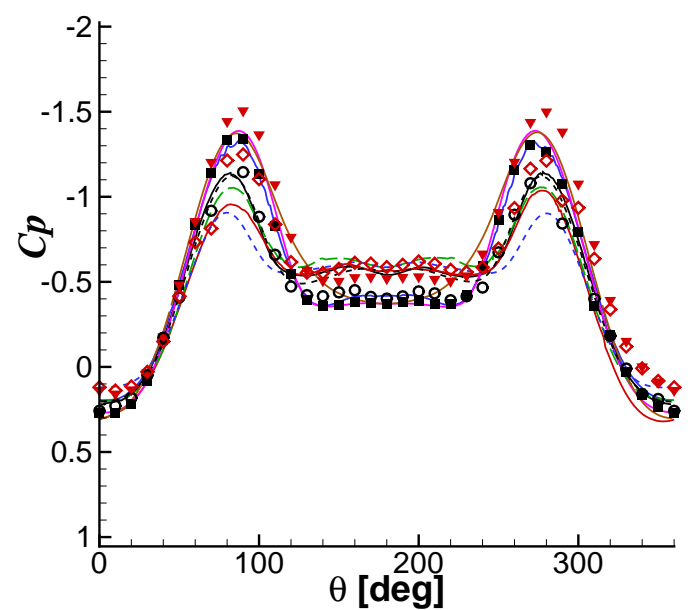

(b) Downstream Cylinder

Figure 8. Time-averaged coefficient of pressure on both cylinders for other methods.

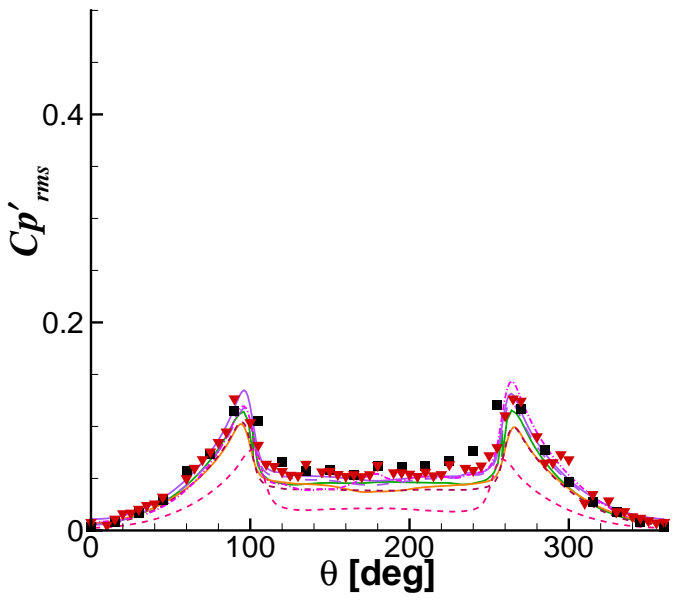

(a) Upstream Cylinder

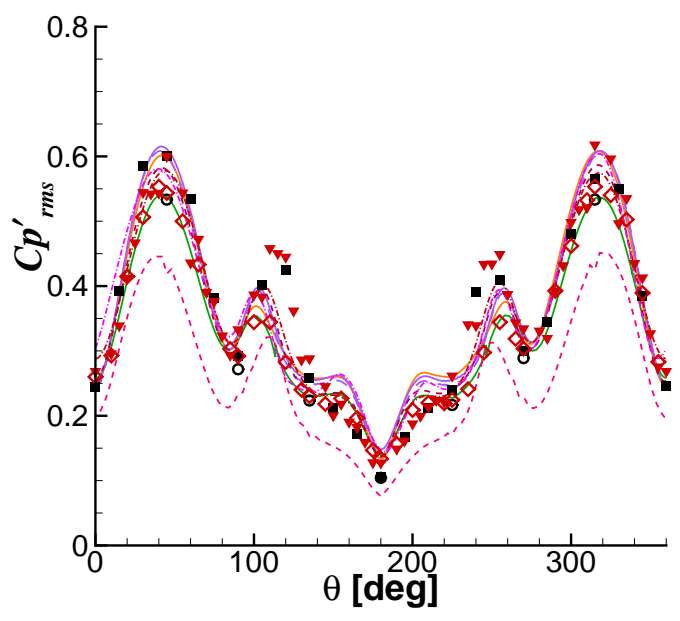

(b) Downstream Cylinder

Figure 9. RMS of the coefficient of pressure on both cylinders from codes using S-A DDES.

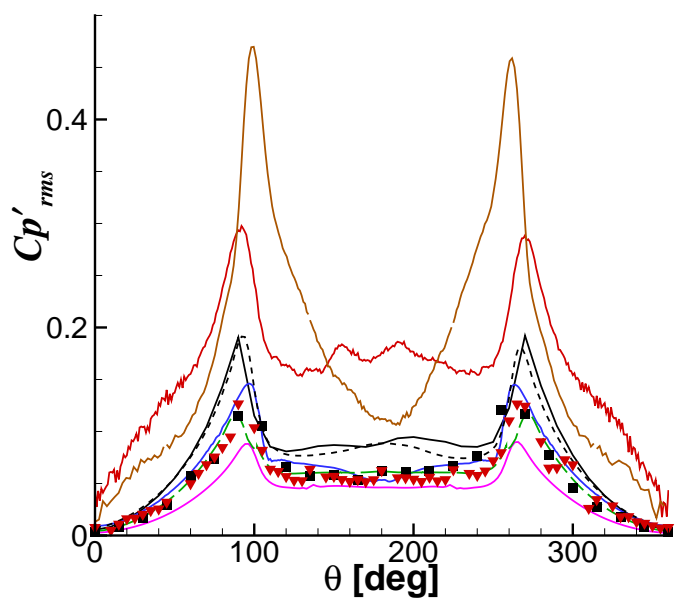

(a) Upstream Cylinder

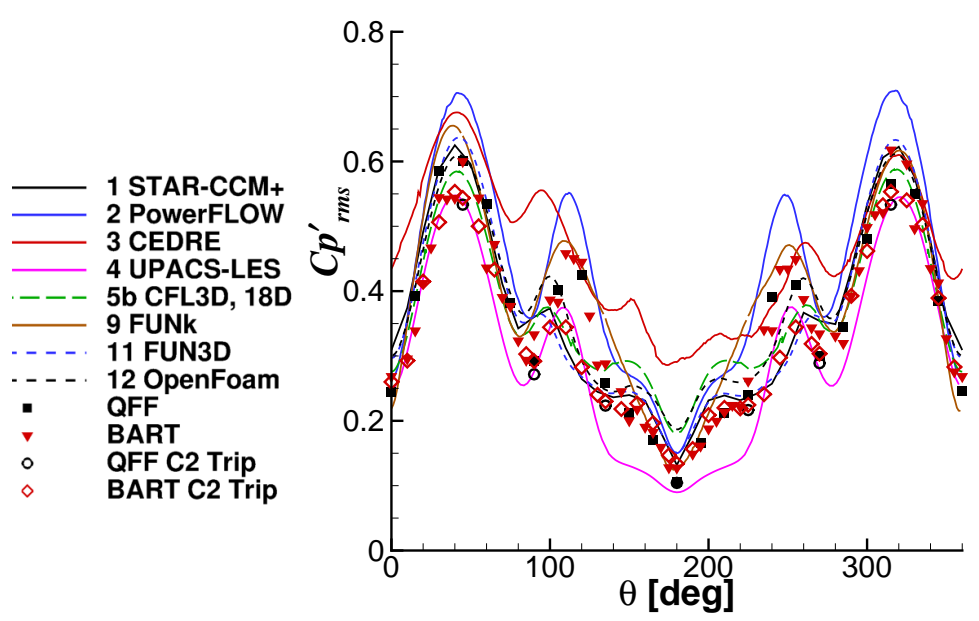

(b) Downstream Cylinder

Figure 10. RMS of the coefficient of pressure on both cylinders for other methods. 


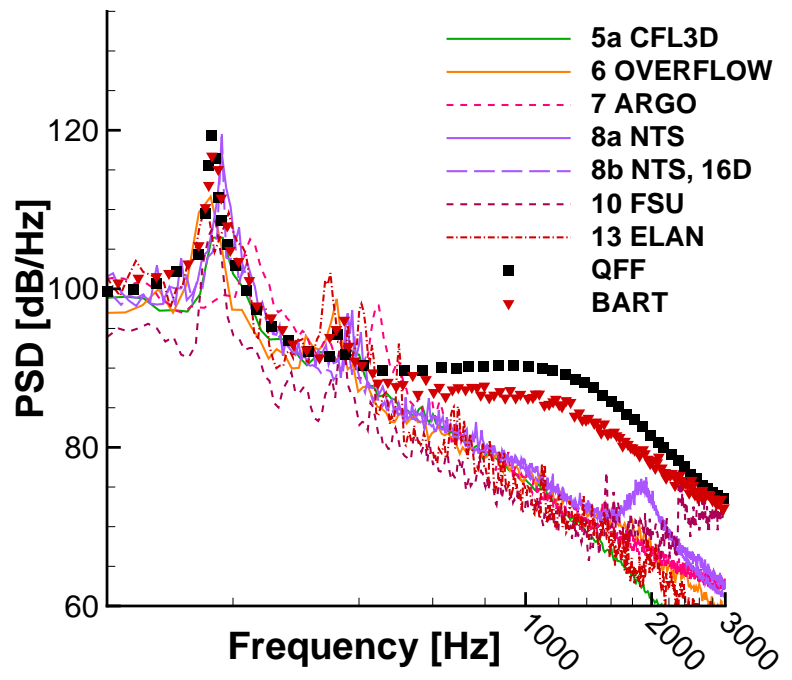

(a) Upstream Cylinder, $\theta=135^{\circ}$

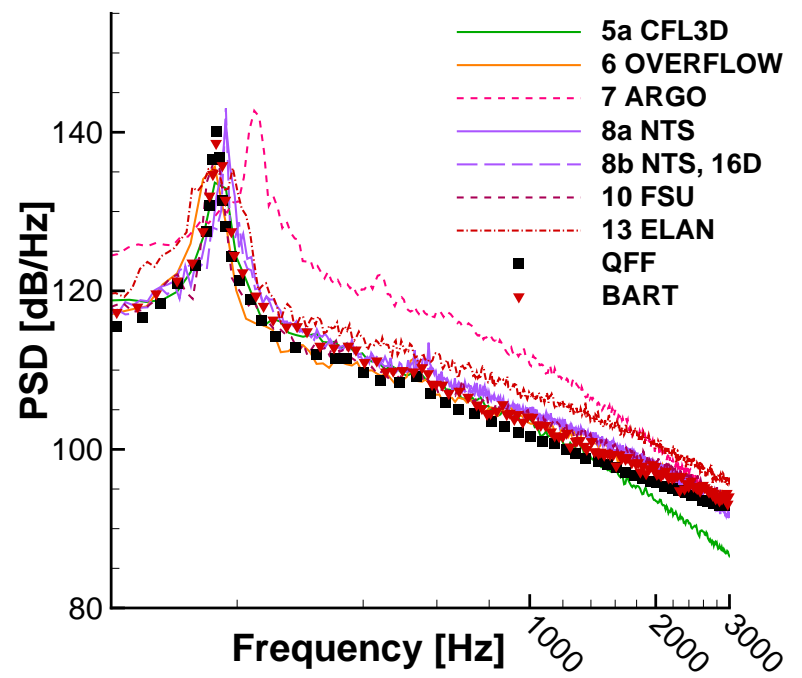

(b) Downstream Cylinder, $\theta=45^{\circ}$

Figure 11. Power spectral density of the pressure on both cylinders from codes using S-A DDES.

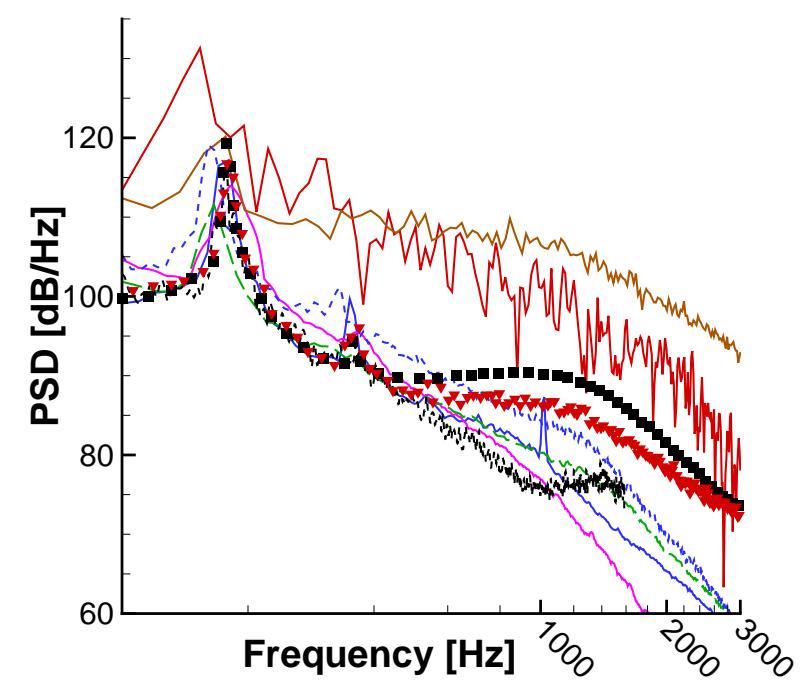

(a) Upstream Cylinder, $\theta=135^{\circ}$

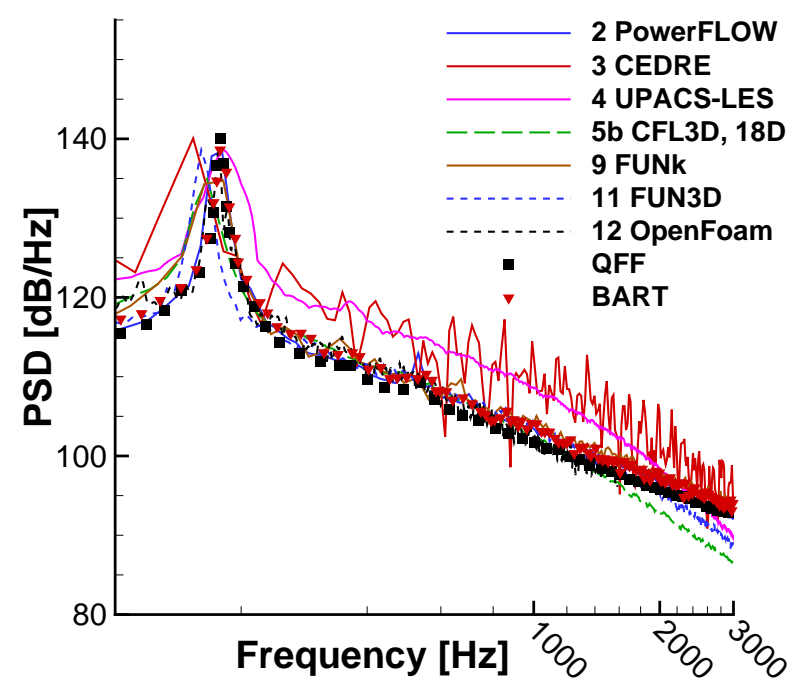

(b) Downstream Cylinder, $\theta=45^{\circ}$

Figure 12. Power spectral density of the pressure on both cylinders for other methods. 


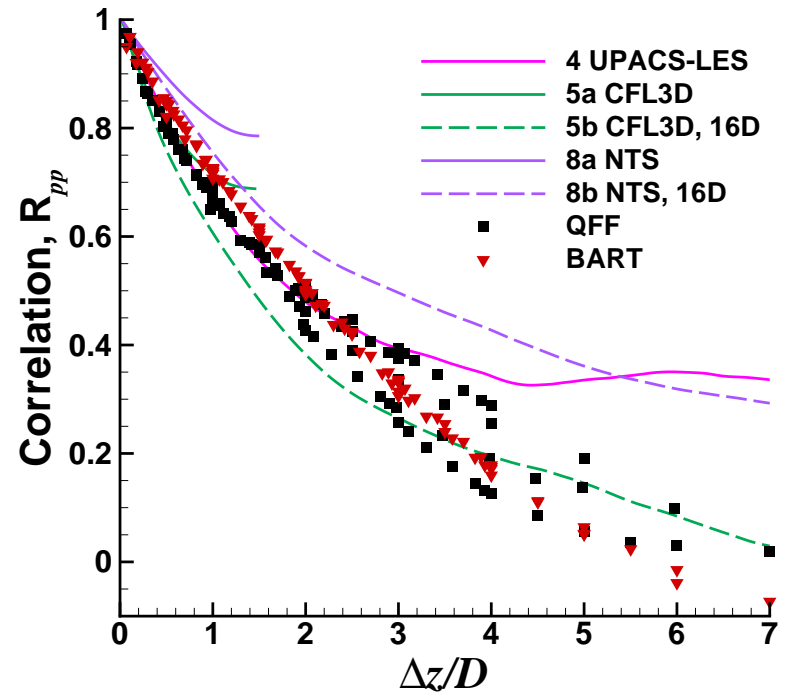

(a) Upstream Cylinder, $\theta=135^{\circ}$

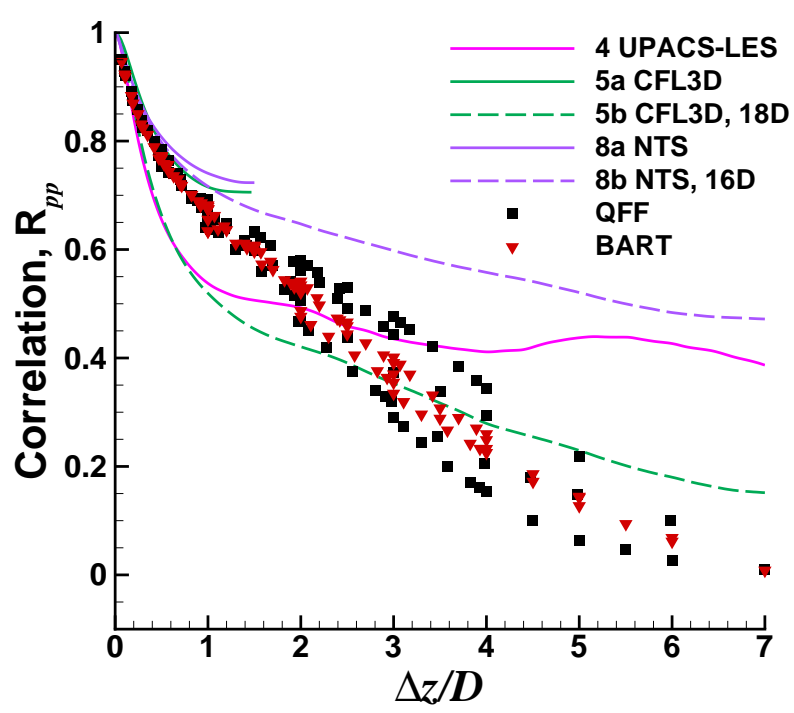

(b) Downstream Cylinder, $\theta=135^{\circ}$

Figure 13. Spanwise correlation of the pressure on both cylinders.

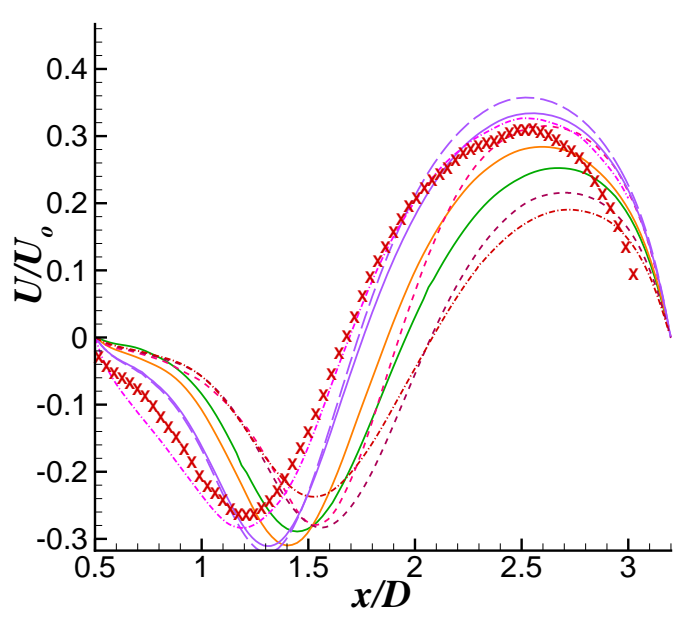

(a) Gap

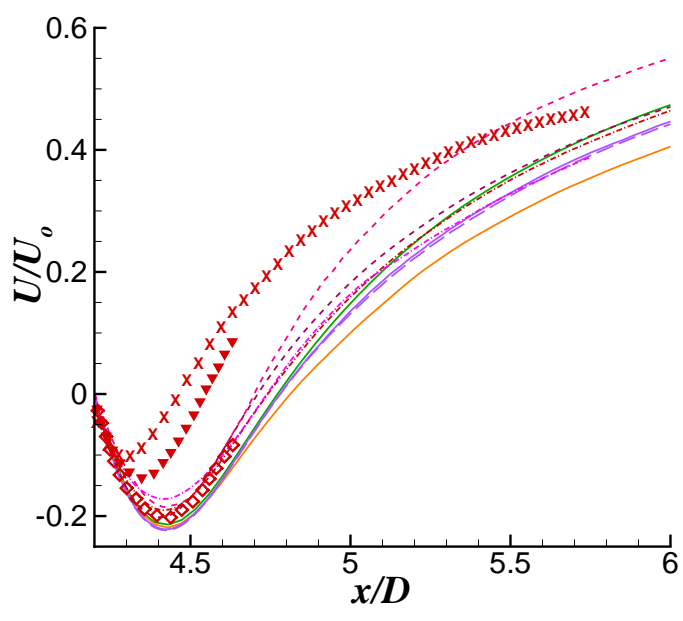

(b) Downstream of $\mathrm{C} 2$

Figure 14. Streamwise velocity along $y=0$ from codes using S-A DDES.

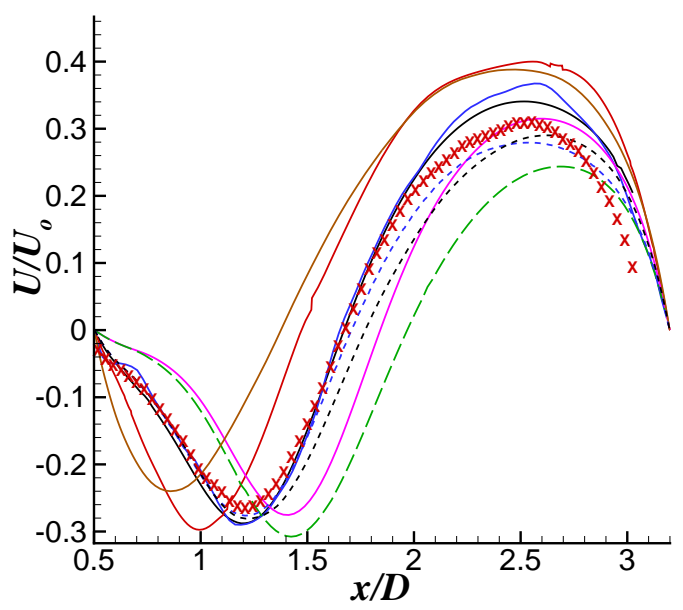

(a) Gap

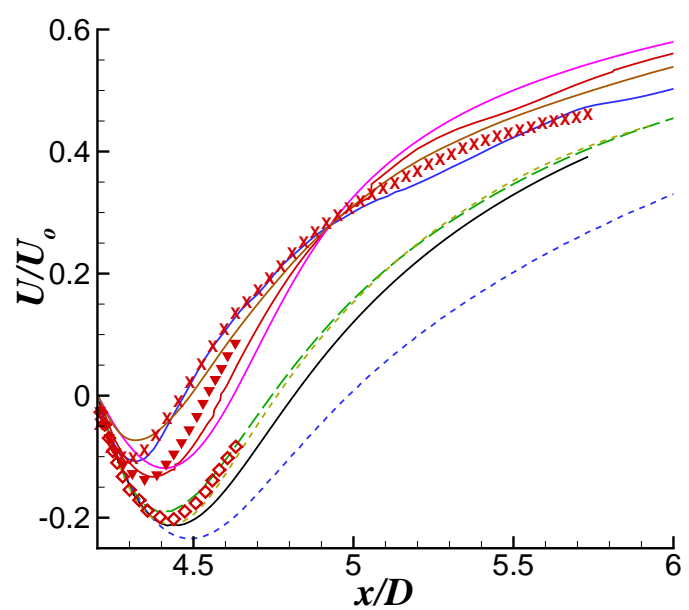

(b) Downstream of C2

Figure 15. Streamwise velocity along $y=0$ for other methods. 


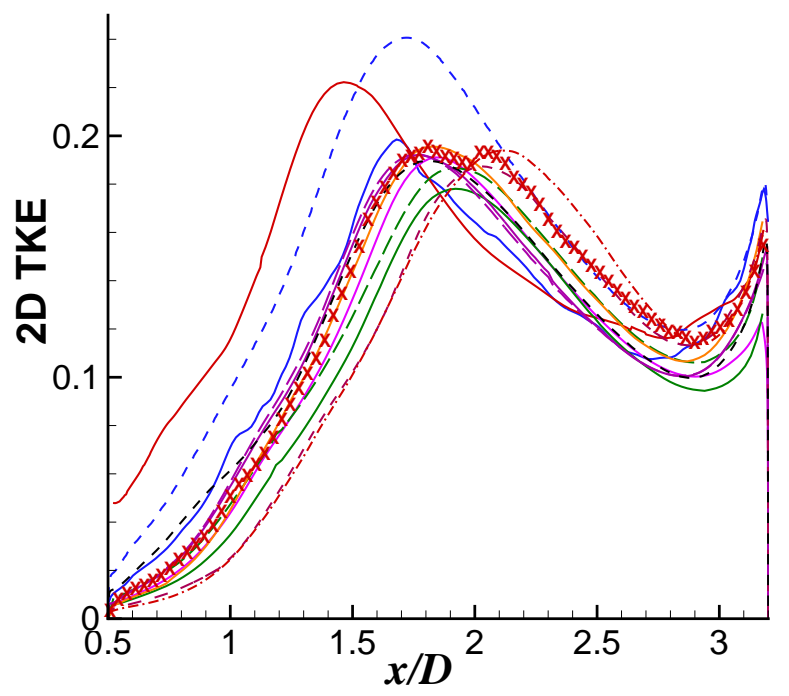

(a) Gap Region

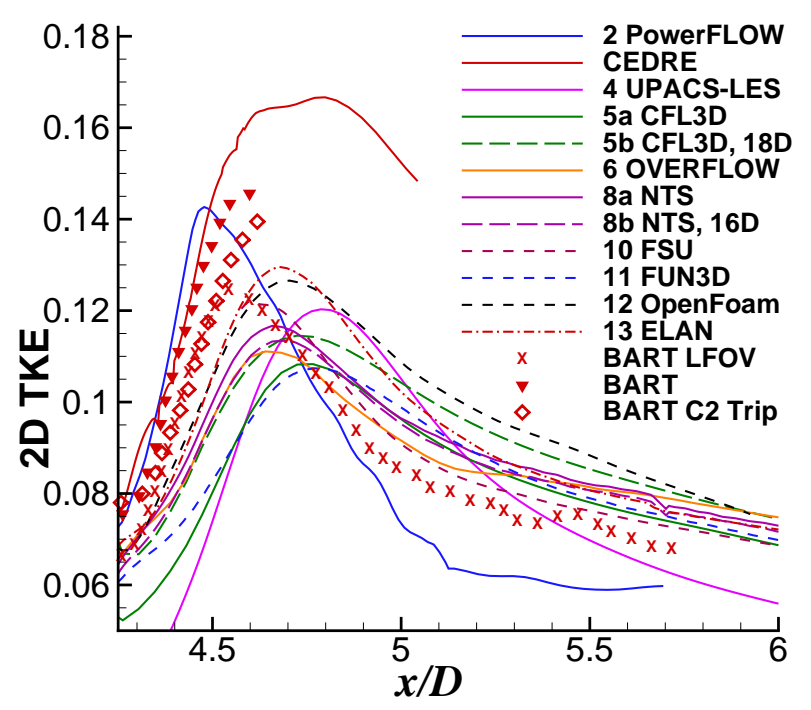

(b) Downstream of C2

Figure 16. 2D turbulence kinetic energy along $y=0$.

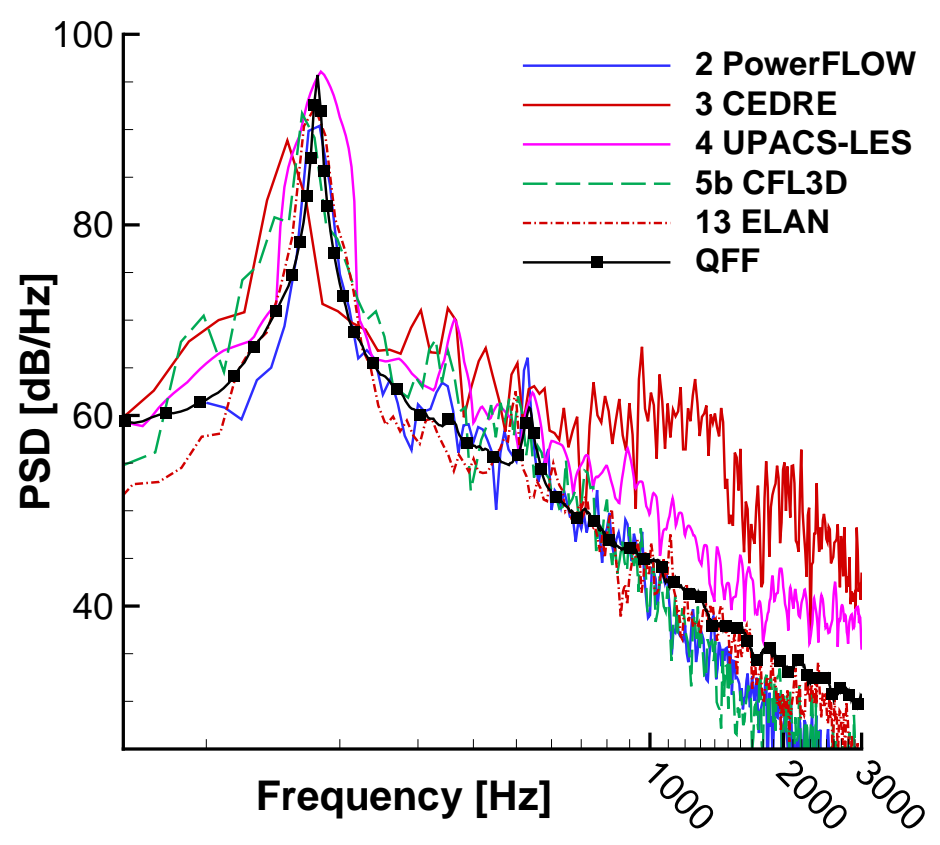

Figure 17. Spectra at the microphone located at (9.11D, 32.49D).

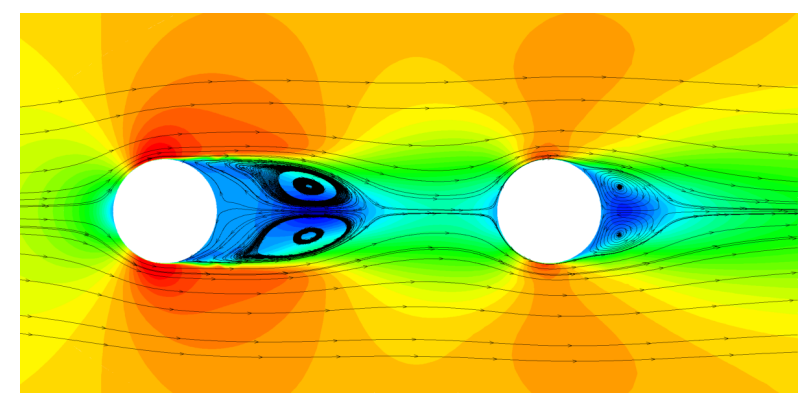

(a) State 1

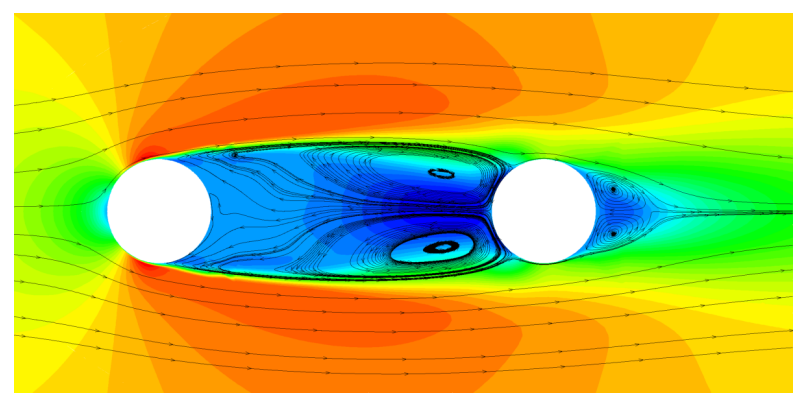

(b) State 2

Figure 18. Streamlines superimposed on contours of the time-averaged total velocity field. 
Table 1. Contributor information.

\begin{tabular}{|c|l|l|}
\hline ID & Organization & Contributors \\
\hline \hline 1 & CD Adapco & O. Aybay \\
\hline 2 & EXA & G. Bres \\
\hline 3 & ONERA & F. Houssen, F. Vuillot, E. Manoha and S. Redonnet \\
\hline 4 & JAXA & T. Imamura, T. Hirai, S. Enomoto and K. Yamamoto \\
\hline 5a & NASA & D. Lockard \\
\hline 5b & NASA & D. Lockard \\
\hline 6 & NASA & D. Lockard and P. Buning \\
\hline 7 & UCL & Y. Marichal, L. Bricteux, M. Duponcheel, G. Winckelmans, C. Carton de Wiart and P. Geuzaine \\
\hline 8 a & NTS & A. Garbaruk, M. Shur, M. Strelets, P. R. Spalart and R. Balakrishnan \\
\hline 8 b & NTS & A. Garbaruk, M. Shur, M. Strelets, P. R. Spalart and R. Balakrishnan \\
\hline 9 & ONERA & M. Terracol \\
\hline 10 & FSU & A. Uzun and M. Y. Hussaini \\
\hline 11 & NASA & V. Vatsa \\
\hline 12 & Southampton & M. Weinmann, R. D. Sandberg and C. J. Doolan \\
\hline 13 & TUB & B. Greschner, C. Mockett and F. Thiele \\
\hline 14 & DLR & K. Weinman \\
\hline 15 & Stanford & C. C. Yu, W. R. Wolf, R. Bhaskaran and S. K. Lele \\
\hline
\end{tabular}


Table 2. Codes and computation information.

\begin{tabular}{|c|l|l|l|c|c|c|l|}
\hline ID & Organization & Submitter & Code & $\begin{array}{c}\text { Convective } \\
\text { Order }\end{array}$ & $\begin{array}{c}\text { Viscous } \\
\text { Order }\end{array}$ & $\begin{array}{c}\text { Turb. } \\
\text { Order }\end{array}$ & Grid Type \\
\hline \hline 1 & CD Adapco & Aybay & STAR-CCM+ & 2 & 2 & & Embedded Cartesian \\
\hline 2 & EXA & Bres & PowerFLOW & 2 & 2 & 2 & Embedded Cartesian \\
\hline 3 & ONERA & Houssen & CEDRE & 2 & 2 & 1 & Structured \\
\hline 4 & JAXA & Imamura & UPACS-LES & 2 & 2 & & Structured \\
\hline $5 \mathrm{a}$ & NASA & Lockard & CFL3D & 2 & 2 & 1 & Structured \\
\hline 5b & NASA & Lockard & CFL3D & 2 & 2 & 1 & Structured \\
\hline 6 & NASA & Lockard & OVERFLOW & 5 & 2 & 1 & Overset Structured \\
\hline 7 & UCL & Marichal & ARGO & 2 & 2 & & Unstructured \\
\hline $8 \mathrm{a}$ & NTS & Strelets & in-house & 4 CD / 5UW & 2 & 1 & Overset Structured \\
\hline $8 \mathrm{~b}$ & NTS & Strelets & in-house & 4 CD / 5UW & 2 & 1 & Overset Structured \\
\hline 9 & ONERA & Terracol & FUNk & 2 & 2 & & Structured \\
\hline 10 & FSU & Uzun & in-house & 4 & 4 & & Overset Structured \\
\hline 11 & NASA & Vatsa & FUN3D & 2 & 2 & 1 & Unstructured \\
\hline 12 & Southampton & Weinmann & OpenFOAM & 2 & 2 & 2 & Structured \\
\hline 13 & TUB & Greschner & ELAN & 2 & 2 & & Structured \\
\hline 14 & DLR & Weinman & TAU & 2 & 2 & 2 & Unstructured \\
\hline
\end{tabular}

Table 3. Details of computations. Reported time steps would simulate 1 second of real time.

\begin{tabular}{|c|l|l|l|c|c|c|c|}
\hline ID & Code & $\begin{array}{l}\text { Turbulence } \\
\text { Model }\end{array}$ & $\begin{array}{l}\text { Time Step } \\
\text { Algorithm }\end{array}$ & Span/D & $\begin{array}{c}\text { Grid Points } \\
\text { (millions) }\end{array}$ & $\begin{array}{c}\text { Time } \\
\text { Steps }\end{array}$ & $\begin{array}{c}\text { Subiterations } \\
\text { Per Time Step }\end{array}$ \\
\hline 1 & STAR-CCM+ & SST DES & & 12 & 6.7 & 100000 & 5 \\
\hline 2 & PowerFLOW & k- $\epsilon$ DES & Explicit & 16 & 66 & 1360874 & 1 \\
\hline 3 & CEDRE & SST DDES & Implicit RKI2 & 4 & 17 & 1000000 & 20 \\
\hline 4 & UPACS-LES & Zonal S-A & MFGS & 18 & 70 & 297463 & 5 \\
\hline $5 \mathrm{a}$ & CFL3D & S-A MDDES & Dual-time & 3 & 10 & 59000 & 20 \\
\hline $5 \mathrm{~b}$ & CFL3D & Zonal SST & Dual-time & 18 & 60 & 59000 & 20 \\
\hline 6 & OVERFLOW & S-A MDDES & Dual-time & 3 & 16 & 233973 & 20 \\
\hline 7 & ARGO & S-A DDES & Dual-Time & 4 & 10 & 100000 & \\
\hline $8 \mathrm{a}$ & NTS Code & S-A DDES & Dual-time & 3 & 11 & 38461 & 15 \\
\hline $8 \mathrm{~b}$ & NTS Code & S-A DDES & Dual-time & 16 & 60 & 153846 & 30 \\
\hline 9 & FUNk & LES & Implicit Gear & 4 & 16 & 500000 & 5 \\
\hline 10 & FSU Code & S-A DDES & Implicit B-W & 6 & 133 & 512820 & 3 \\
\hline 11 & FUN3D & HRLES & Dual-time & 3 & 8.7 & 59200 & 15 \\
\hline 12 & OpenFOAM & FSM SST & pisoFOAM & 3 & 2 & 325287 & \\
\hline 13 & ELAN & S-A DDES & Implicit & 3 & 10 & 40000 & 10 \\
\hline 14 & TAU & S-A DDES & Dual-time & 3 & 11 & 14000 & 150 \\
\hline
\end{tabular}


Table 4. Wall clock time to generate 1 second of simulation data. $I B=$ Infiniband and $G b=$ Gigabit ethernet.

\begin{tabular}{|c|l|c|c|c|l|c|}
\hline ID & Code & $\begin{array}{c}\text { Wall Clock } \\
\text { Hours }\end{array}$ & $\begin{array}{c}\text { \# CPU } \\
\text { Cores }\end{array}$ & $\begin{array}{c}\text { CPU } \\
\text { Years }\end{array}$ & $\begin{array}{l}\text { CPU } \\
\text { Type }\end{array}$ & Interconnect \\
\hline 1 & STAR-CCM+ & & & & & \\
\hline 2 & PowerFLOW & 446 & 112 & 5.7 & AMD Opt 280 & IB \\
\hline 3 & CEDRE & 600 & 256 & 17.5 & Intel Nehalem 2.8GHz & IB \\
\hline 4 & UPACS-LES & 2662 & 143 & 43.5 & AMD Opt 2222SE & $\mathrm{Gb}$ \\
\hline $5 \mathrm{a}$ & CFL3D & 921 & 77 & 8.1 & Intel 3.6 P4 & $\mathrm{Gb}$ \\
\hline $5 \mathrm{~b}$ & CFL3D & 3868 & 77 & 34.0 & Intel 3.6 P4 & $\mathrm{Gb}$ \\
\hline 6 & OVERFLOW & 8903 & 128 & 130.1 & Intel 2.8 P4 & $\mathrm{Gb}$ \\
\hline 7 & ARGO & 1080 & 400 & 49.3 & Intel L5420 & $\mathrm{IB}$ \\
\hline $8 \mathrm{a}$ & NTS Code & 1584 & 32 & 5.8 & Intel E5345 & $\mathrm{Gb}$ \\
\hline $8 \mathrm{~b}$ & NTS Code & 528 & 8160 & 491.8 & Power PC & $\mathrm{IB}$ \\
\hline 9 & FUNk & 1000 & 4 & 0.5 & NEC SX-8R & \\
\hline 10 & FSU Code & 2367 & 816 & 220.5 & AMD Opt 2.3 GHz & $\mathrm{IB}$ \\
\hline 11 & FUN3D & 532 & 256 & 15.5 & Intel E3110 & $\mathrm{Gb}$ \\
\hline 12 & OpenFOAM & 108 & 128 & 1.6 & Intel E5520 & $\mathrm{IB}$ \\
\hline 13 & ELAN & 578 & 72 & 4.8 & Intel Harpertown & $\mathrm{IB}$ \\
\hline 14 & TAU & 2112 & 128 & 30.9 & AMD Barcelona & IB \\
\hline
\end{tabular}


Table 5. Lift and drag results for the upstream cylinder.

\begin{tabular}{|c|c|c|c|c|c|c|c|}
\hline ID & Code & $\mathrm{f}[\mathrm{Hz}]$ & $C_{D}$ & $\operatorname{rms} C_{L}^{\prime}$ & $\operatorname{rms} C_{D}^{\prime}$ & $\operatorname{rms} \partial C_{L} / \partial t$ & $\operatorname{rms} \partial C_{D} / \partial t$ \\
\hline 1 & STAR-CCM+ & 171.9 & 0.64 & & & & \\
\hline 2 & PowerFLOW & 179 & 0.59 & 0.108 & 0.010 & 118.8 & 8.3 \\
\hline 3 & CEDRE & 153 & 0.80 & & & & \\
\hline 4 & UPACS-LES & 181.3 & 0.48 & 0.035 & 0.010 & 40.2 & 6.7 \\
\hline $5 a$ & CFL3D & 177 & 0.36 & 0.046 & 0.013 & 61.9 & 17.2 \\
\hline $5 b$ & CFL3D & 166 & 0.43 & 0.049 & 0.006 & 32.3 & 3.9 \\
\hline 6 & OVERFLOW & 176 & 0.50 & 0.072 & 0.018 & 100.5 & 28.6 \\
\hline 7 & ARGO & 226 & 0.33 & & & & \\
\hline $8 \mathrm{a}$ & NTS Code & 188 & 0.48 & 0.078 & 0.018 & 90.3 & 16.9 \\
\hline $8 b$ & NTS Code & 188 & 0.47 & 0.066 & 0.006 & 77.8 & 7.4 \\
\hline 9 & FUNk & 175 & 0.70 & 0.225 & 0.031 & 191.3 & 52.2 \\
\hline 10 & FSU Code & 181 & 0.45 & & & & \\
\hline 11 & FUN3D & 160 & 0.64 & & & & \\
\hline 12 & OpenFOAM & 173 & 0.55 & 0.102 & 0.034 & 108.1 & 15.9 \\
\hline \multirow[t]{9}{*}{13} & ELAN & 175 & 0.44 & 0.054 & 0.032 & 62.9 & 17.7 \\
\hline & Min & 153 & 0.334 & 0.035 & 0.006 & 32.3 & 3.9 \\
\hline & Max & 226 & 0.800 & 0.225 & 0.034 & 191.3 & 52.2 \\
\hline & Median & 176.0 & 0.484 & 0.069 & 0.016 & 84.0 & 16.4 \\
\hline & Mean & 178.0 & 0.525 & 0.084 & 0.018 & 88.4 & 17.5 \\
\hline & Std Deviation & 16.3 & 0.127 & 0.055 & 0.011 & 45.9 & 14.2 \\
\hline & Std Dev/Mean \% & 9.1 & 24.3 & 65.8 & 60.3 & 52.0 & 81.4 \\
\hline & Median/Expt \% & 0.0 & & & & & \\
\hline & Mean/Expt \% & -1.1 & & & & & \\
\hline
\end{tabular}


Table 6. Lift and drag results for the downstream cylinder.

\begin{tabular}{|c|c|c|c|c|c|c|}
\hline ID & Code & $C_{D}$ & $\operatorname{rms} C_{L}^{\prime}$ & $\operatorname{rms} C_{D}^{\prime}$ & $\operatorname{rms} \partial C_{L} / \partial t$ & $\operatorname{rms} \partial C_{D} / \partial t$ \\
\hline 1 & STAR-CCM+ & 0.44 & & & & \\
\hline 2 & PowerFLOW & 0.29 & 0.704 & 0.073 & 776.6 & 156.6 \\
\hline 3 & CEDRE & 0.50 & & & & \\
\hline 4 & UPACS-LES & 0.32 & 0.341 & 0.028 & 393.0 & 84.9 \\
\hline $5 a$ & CFL3D & 0.46 & 0.526 & 0.074 & 763.8 & 154.4 \\
\hline $5 b$ & CFL3D & 0.52 & 0.421 & 0.038 & 281.1 & 39.8 \\
\hline 6 & OVERFLOW & 0.45 & 0.643 & 0.085 & 908.4 & 210.7 \\
\hline 7 & ARGO & 0.35 & & & & \\
\hline $8 a$ & NTS Code & 0.42 & 0.612 & 0.076 & 716.6 & 145.1 \\
\hline $8 b$ & NTS Code & 0.43 & 0.519 & 0.039 & 609.2 & 79.4 \\
\hline 9 & FUNk & 0.47 & 0.733 & 0.079 & 634.3 & 126.6 \\
\hline 10 & FSU Code & 0.42 & & & & \\
\hline 11 & FUN3D & 0.45 & & & & \\
\hline 12 & OpenFOAM & 0.43 & 0.608 & 0.096 & 652.9 & 145.5 \\
\hline \multirow[t]{7}{*}{13} & ELAN & 0.46 & 0.594 & 0.087 & 671.3 & 138.6 \\
\hline & Min & 0.294 & 0.341 & 0.028 & 281.1 & 39.8 \\
\hline & Max & 0.518 & 0.733 & 0.096 & 908.4 & 210.7 \\
\hline & Median & 0.444 & 0.601 & 0.075 & 662.1 & 141.9 \\
\hline & Mean & 0.428 & 0.570 & 0.067 & 640.7 & 128.2 \\
\hline & Std Deviation & 0.062 & 0.122 & 0.024 & 183.7 & 48.4 \\
\hline & Std Dev/Mean \% & 14.5 & 21.3 & 35.0 & 28.7 & 37.7 \\
\hline
\end{tabular}


Table 7. Summary of Results.

\begin{tabular}{|c|c|c|c|c|c|c|c|c|c|c|}
\hline \multirow{2}{*}{ ID } & \multirow[b]{2}{*}{ Code } & \multicolumn{2}{|c|}{ Upstream } & \multicolumn{4}{|c|}{ Downstream } & \multicolumn{2}{|c|}{ Gap } & \multirow{2}{*}{$\begin{array}{l}\mathrm{Aft} \mathrm{C} 2 \\
U \mathrm{~min}\end{array}$} \\
\hline & & $C p \min$ & $C p^{\prime} \max$ & $C p \min$ & $C p \max$ & $C p^{\prime} \min$ & $C p^{\prime} \max$ & $U \min$ & $U \max$ & \\
\hline 1 & STAR-CCM+ & -1.66 & 0.192 & -1.15 & 0.22 & 0.132 & 0.625 & -0.287 & 0.341 & -0.213 \\
\hline 2 & PowerFLOW & -1.56 & 0.146 & -1.33 & 0.20 & 0.150 & 0.709 & -0.290 & 0.367 & -0.108 \\
\hline 3 & CEDRE & -1.49 & 0.298 & -1.03 & 0.32 & 0.286 & 0.676 & -0.297 & 0.400 & -0.133 \\
\hline 4 & UPACS-LES & -1.70 & 0.090 & -1.39 & 0.27 & 0.090 & 0.548 & -0.275 & 0.315 & -0.119 \\
\hline $5 a$ & CFL3D & -1.72 & 0.115 & -1.20 & 0.25 & 0.139 & 0.541 & -0.289 & 0.252 & -0.214 \\
\hline $5 b$ & CFL3D & -1.57 & 0.118 & -1.06 & 0.20 & 0.182 & 0.588 & -0.308 & 0.244 & -0.190 \\
\hline 6 & OVERFLOW & -1.68 & 0.102 & -1.15 & 0.19 & 0.134 & 0.608 & -0.310 & 0.284 & -0.219 \\
\hline 7 & ARGO & -1.90 & 0.078 & -1.49 & 0.36 & 0.076 & 0.452 & -0.279 & 0.315 & -0.186 \\
\hline $8 \mathrm{a}$ & NTS Code & -1.79 & 0.135 & -1.30 & 0.21 & 0.148 & 0.615 & -0.311 & 0.334 & -0.222 \\
\hline $8 \mathrm{~b}$ & NTS Code & -1.80 & 0.123 & -1.31 & 0.23 & 0.141 & 0.608 & -0.321 & 0.357 & -0.225 \\
\hline 9 & FUNk & -1.77 & 0.470 & -1.48 & 0.38 & 0.125 & 0.655 & -0.226 & 0.467 & -0.073 \\
\hline 10 & FSU Code & -1.67 & 0.104 & -1.20 & 0.19 & 0.138 & 0.587 & -0.240 & 0.388 & -0.201 \\
\hline 11 & FUN3D & -1.54 & 0.176 & -0.91 & 0.12 & 0.168 & 0.641 & -0.276 & 0.279 & -0.234 \\
\hline 12 & OpenFOAM & -1.78 & 0.191 & -1.12 & 0.20 & 0.187 & 0.612 & -0.281 & 0.290 & -0.210 \\
\hline 13 & ELAN & -1.72 & 0.105 & -1.24 & 0.15 & 0.137 & 0.578 & -0.237 & 0.19 & -0.190 \\
\hline \multirow[t]{12}{*}{14} & TAU & -1.71 & 0.143 & -1.20 & 0.22 & 0.147 & 0.604 & -0.284 & 0.327 & -0.171 \\
\hline & QFF & -1.68 & 0.121 & -1.34 & 0.27 & 0.105 & 0.600 & & & \\
\hline & BART & -1.85 & 0.127 & -1.50 & 0.16 & 0.127 & 0.618 & -0.266 & 0.309 & -0.138 \\
\hline & BART C2 Trip & -1.85 & 0.127 & -1.25 & 0.14 & 0.132 & 0.57 & -0.266 & 0.309 & -0.202 \\
\hline & Min & -1.90 & 0.078 & $\begin{array}{l}-1.49 \\
\end{array}$ & 0.12 & 0.076 & 0.452 & -0.321 & 0.216 & -0.234 \\
\hline & $\operatorname{Max}$ & -1.49 & 0.470 & -0.91 & 0.38 & 0.286 & 0.709 & -0.240 & 0.400 & -0.073 \\
\hline & Median & -1.69 & 0.129 & -1.20 & 0.215 & 0.14 & 0.61 & -0.288 & 0.315 & -0.206 \\
\hline & Mean & -1.69 & 0.167 & -1.222 & 0.239 & 0.149 & 0.604 & -0.289 & 0.313 & -0.182 \\
\hline & Std Deviation & 0.117 & 0.104 & 0.170 & 0.072 & 0.049 & 0.063 & 0.020 & 0.055 & 0.051 \\
\hline & Std Dev/Mean \% & -6.9 & 62.3 & -13.9 & 30.0 & 33.1 & 10.4 & -7.0 & 17.7 & -28.3 \\
\hline & Median/Expt \% & -8.6 & 1.6 & -3.2 & 54.7 & 6.1 & 7.0 & 8.3 & 1.9 & 1.7 \\
\hline & Mean/Expt \% & -8.8 & 31.5 & -1.4 & 71.7 & 12.5 & 6.0 & 8.7 & 1.3 & -10.0 \\
\hline
\end{tabular}

